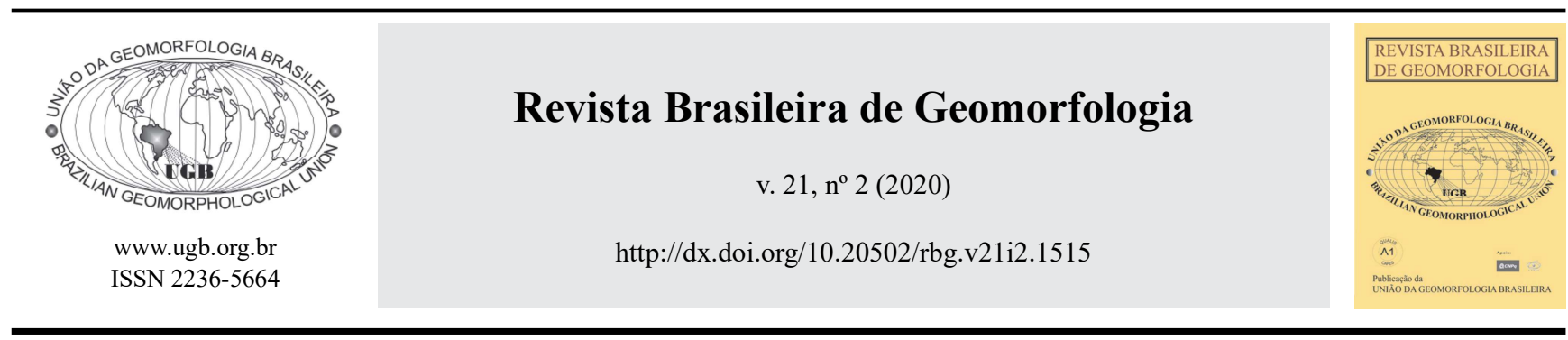

\title{
ANÁLISE MORFOMÉTRICA EM BACIAS AFETADAS POR FLUXOS DE DETRITOS NA REGIÃO SERRANA DO RIO DE JANEIRO
}

\section{MORPHOMETRIC ANALYSIS OF WATERSHED AFFECTED BY DEBRIS FLOWS IN MOUNTAIN REGION OF RIO DE JANEIRO}

\author{
Ingrid Ferreira Lima \\ Instituto de Geociencias, Universidade Federal do Rio de Janeiro \\ Av. Athos da Silveira Ramos, 274, Rio de Janeiro, Rio de Janeiro. CEP: 21945-970. Brasil \\ ORCID: 0000-0002-5263-377X \\ E-mail: lima.ingridf@gmail.com \\ Nelson Ferreira Fernandes \\ Instituto de Geociencias, Universidade Federal do Rio de Janeiro \\ Av. Athos da Silveira Ramos, 274, Rio de Janeiro, Rio de Janeiro. CEP: 21945-970. Brasil \\ ORCID: 0000-0003-4747-3342 \\ E-mail:nelsonff@acd.ufrj.br
}

Eurípedes do Amaral Vargas Junior Instituto de Geociencias, Universidade Federal do Rio de Janeiro Cidade Universitária, Ilha do Fundão, Rio de Janeiro. CEP: 21945-970. Brasil ORCID: 0000-0002-7528-4138

E-mail:vargas@puc-rio.br

\begin{tabular}{l} 
Informações sobre o Artigo \\
Recebido (Received): \\
20/08/2018 \\
Aceito (Accepted): \\
12/03/2020 \\
\hline
\end{tabular}

\section{Palavras-chave:}

Fluxos de Detritos; Análise do Terreno; Índices Morfométricos; Serra do Mar.

\section{Keywords:}

Debris Flows; Terrain Analysis; Morphometric Indices.

\begin{abstract}
Resumo:
Os processos geomorfológicos relacionados a fluxos de detritos são os mais catastróficos da natureza devido à sua alta velocidade, energia cinemática e grande volume de sedimentos mobilizados. Os danos e os prejuízos econômicos provocados por este movimento têm sido significativos para vidas humanas, terras agrícolas, assentamentos e propriedades. Portanto, é essencial compreendermos as características das áreas fonte e áreas de deposição para planejar a mitigação de desastres. Índices morfométricos na escala de bacia são bastante úteis para compreender a iniciação, propagação e deposição de fluxo de detritos, melhorando a avaliação da suscetibilidade e geração de mapas de perigos. Este artigo caracteriza os índices morfométricos nas áreas que ocorreram os fluxos de detritos que afetaram quatro bacias (Cuiabá, Príncipe, Vieira e D’Antas) situadas no reverso da Serra do Mar fluminense. Os índices incluem o Ângulo de Encosta, Índice Topográfico de Umidade (ITU), Índice de Potência Unitária de Corrente (IPUC) e Fator Topográfico (LS). Os índices morfométricos foram derivados de modelos digitais de terreno (12,5-m de resolução) usando ambiente de Sistema de Informações Geográficas. Os resultados mostram que o fluxo de detritos foi deflagrado em amplitude $>1.200 \mathrm{~m}$, Ângulos de Encosta $>45^{\circ}$, por
\end{abstract}


escorregamentos nos taludes laterais ou na cabeceira de drenagem e desenvolvidas no canal principal com valores altos de ITU, IPUC e LS. Os fluxos de detritos foram depositados em Ângulos de Encosta $<2^{\circ}$ em bacias com altos valores de ITU e IPUC (exceto Príncipe e Vieira) e baixos valores de LS. Portanto, os índices indicaram as classes críticas para a ocorrência das fases de fluxos dos detritos das bacias analisadas.

\begin{abstract}
:
The geomorphological processes related to debris flow are the most catastrophic in nature because of their high velocity, kinematic energy, and large volume of mobilized sediments. The damage and economic losses caused by this movement have been significant for human lives, agricultural lands, settlements, and properties. Thus, understanding the characteristics of the source area and deposition area is essential for debris-flow mitigation. Basin-scale morphometric indices are very useful for understanding debris flow initiation, propagation, and deposition, improving susceptibility assessment and hazard map generation. The present article characterizes the morphometric indices in areas where debris flows occurred affecting four basins (Cuiabá, Príncipe, Vieira, and D’Antas) located on the reverse of Serra do Mar fluminense. The indices herein considered include Slope Angle, Topographic Wetness Index (TWI), Stream Power Index (SPI), and Topographic Factor (LS). The morphometric indices were derived from Digital Terrain Models (DTM) (at 12.5-m resolution) using the Geographic Information System environment. The results show that the debris flow was triggered in amplitude $>1200 \mathrm{~m}$, slope angles $>45^{\circ}$, by landslides developed in the main channel with high values of TWI, SPI, and LS. Debris flows were deposited at slope angles $<2^{\circ}$ in watershed with high TWI and SPI (except Príncipe and Vieira watersheds) and low Topographic Factor (LS) values. Therefore, the indices indicated the critical classes for the occurrence of debris flow phases of the analyzed watersheds.
\end{abstract}

\section{Introdução}

O fluxo de detritos é um movimento de massa do tipo rápido, caracterizado por mobilizar grande quantidade de material e com extenso raio de alcance, mesmo em áreas planas, que se desenvolve numa forma de fluxo concentrado nos canais de drenagem (SIDLE \& OCHIAI, 2006; HUNGR et al., 2013). Esse fluxo ocorre, normalmente, em bacias com alto gradiente hipsométrico e é caracterizado por: i) uma zona de iniciação; ii) uma zona de transporte canalizada; e iii) uma zona de deposição a jusante, caracterizada pela formação de leques deposicionais (HUNGR, 2005).

As características morfométricas em escala da bacia hidrográfica podem conter informações importantes sobre a formação e desenvolvimento da bacia, pois todos os processos hidrogeomorfológicos ocorrem dentro dela. Os trabalhos pioneiros sobre índices morfométricos e avaliação de fluxo de detritos foram iniciados nos anos 60 e alguns estudos de caso foram realizados nos anos 80 (BERTRAND et al., 2012). Recentemente, os índices morfométricos têm sido amplamente utilizados para identificar bacias hidrográficas suscetíveis ao fluxo de detritos em diferentes ambientes geomorfológicos no mundo (WILFORD et al., 2004; WELSH \& DAVIES, 2011). No Brasil, diversos autores apontam as vantagens da aplicação de critérios morfométricos na delimitação de bacias de drenagem com alta suscetibilidade à geração de fluxo de detritos. Picanço et al. (2016) citam que parâmetros morfométricos em escala de bacia são bastante úteis para entender a origem, o desenvolvimento $\mathrm{e}$ a deposição de fluxo de detritos, melhorando os mapas de suscetibilidade e risco. Vieira et al. (2019), por sua vez, apresentaram exemplos de aplicações de análises morfométricas do relevo (densidade de drenagem, índice de rugosidade, hierarquia de drenagem e índice de Melton) na identificação de áreas sujeitas à ocorrência de corridas de detritos em locais afetados na Serra do Mar do Sul e Sudeste brasileiro.

Sistemas de Informações Geográficas são usados para avaliar vários parâmetros morfométricos e de terreno das bacias, pois fornecem um ambiente flexível e uma ferramenta poderosa para a manipulação e análise de informações espaciais. Chen e Yu (2011), por exemplo, aplicaram os índices Fator de Forma, Razão Elevação-Relevo, Ângulo de Encosta, Índice de Potência Unitária de Corrente e Índice Topográfico de Umidade, derivados de Modelos Digitais de Elevação de 10-m de resolução, nas regiões norte e central de Taiwan e mostraram que os fluxos de detritos tendem a iniciar a partir de encostas íngremes (ângulo de encosta de $30^{\circ}-45^{\circ}$ ) ou de escorregamentos com valores mais altos de Índice Topográfico de Umidade (ITU). Além 
disso, o Índice de Potência Unitária de Corrente sofreu um aumento após a ocorrência do processo. No Brasil, Dias et al. (2015) e Nery (2016) estudaram os fluxos de detritos em bacias de drenagem da Serra do Mar paulista e identificaram a influência baixa do Índice de Circularidade para explicar diferentes magnitudes de fluxos de detritos em bacias. Sendo assim, considera-se necessária a avaliação de outros parâmetros morfométricos relacionados à ocorrência de fluxos de detritos.

A fim de caracterizar e distinguir entre fluxos de detritos e inundações de detritos, Wilford et al. (2004) aplicaram os índices Relação de Relevo, Índice de Melton, Ângulos de Encosta $\left(30^{\circ}-40^{\circ}\right)$, Comprimento da Bacia e Área da Bacia. Esses autores utilizaram esses índices morfométricos para classificar os processos hidrogeomorfológicos com base nas assinaturas de 65 depósitos de sedimentos na região centro-ocidental da Colúmbia Britânica, Canadá. De acordo com Wilford et al. (2004), o Índice de Melton (R) e o Comprimento da Bacia $(\mathrm{Cb})$ são os fatores mais eficazes na distinção entre fluxos de detritos e inundações de detritos; para eles, a bacia mais suscetível a fluxos de detritos tem $\mathrm{R}$ $>0,6$ e $\mathrm{Cb}<2,7 \mathrm{~km}$, enquanto Welsh e Davies (2011) afirmam que valores de $\mathrm{R}>0,5$ podem ser suficientes para o desenvolvimento de fluxos de detritos.

Com base nos resultados de Wilford et al. (2004), pesquisadores brasileiros aplicaram o Índice de Melton associado ao Comprimento da Bacia Hidrográfica e/ou ao Gradiente do Depósito para distinguir os processos de inundação, inundação de detritos e fluxo de detritos dominantes em bacias de drenagem para diferentes paisagens geoambientais brasileiras (ARRUDA JR. \& LOPES, 2014; CORSI et al., 2015). Por exemplo, Ferreira et al. (2016) realizaram uma análise regional de suscetibilidade e risco ao fluxo de detritos em 106 bacias do município de Itaoca, São Paulo, afetadas por fluxos de detritos ocorridos em 2014. Esses autores selecionaram oito índices: Declividade entre $30^{\circ} \mathrm{e}$ $40^{\circ}$ (Índice D30-40), Diferença de Cotas, Densidade de Drenagem, Índice de Circularidade, Comprimento da Bacia, Razão de Relevo, Índice de Melton e Índice de Risco de Escorregamento. Segundo os autores, os índices mais influentes foram Índice D30-40, Razão de Relevo e Índice de Melton, pois estes mostraram um aumento constante nos valores das classes mais baixas para a mais alta, enquanto os demais atributos tiveram padrão menos regular em relação às classes de suscetibilidade/risco.
Tunusluoglu et al. (2007) combinaram Índice de Potência Unitária de Corrente (IPUC), Aspecto, Elevação, Fator Topográfico (LS), Curvatura de Plano, Curvatura de Perfil e Ângulo de Encosta para produzir um mapa de suscetibilidade de áreas de origem de detritos no sudoeste da Turquia por meio de uma regressão logística.

Raramente o fluxo de detritos pode ser associado a um único e definitivo fator condicionante. Por conta disto, o processo deve ser observado como produto de uma cadeia de fatores que acabam determinando a sua deflagração, propagação e deposição.

O presente estudo está focado na Região Serrana do Estado do Rio de Janeiro, que é historicamente associada a movimentos de massa, especialmente fluxo de detritos, com alto números de vítimas fatais e extensos custos econômicos devido à presença de vertentes com elevados gradientes, amplitudes topográficas expressivas, maciços rochosos muito fraturados, depósitos de tálus e solos residuais delgados dispostos diretamente sobre rocha.

Dentro deste contexto, o objetivo principal do presente estudo é aplicar os índices morfométricos Ângulo de Encosta, ITU, IPUC e LS para caracterizar a distribuição espacial da ocorrência de fluxos de detritos em quatro bacias no reverso da Serra do Mar fluminense usando análise estatística baseada em Sistemas de Informações Geográficas (SIG), Modelos Digitais do Terreno (MDT) e investigações de campo.

\section{2. Área de Estudo}

A área de interesse está situada na Região Serrana do Estado do Rio de Janeiro, que foi palco do mega desastre ocorrido na madrugada de 12 de janeiro de 2011. Segundo Lima (2013), diversos movimentos de massa generalizados em encostas e ao longo de canais de drenagem que cruzam sete municípios, deflagrados por chuvas extremas vindas do norte, deixaram 20.000 desabrigados, resultaram em $\mathrm{R} \$ 4,5$ bilhões em prejuízos econômicos e, principalmente, causaram 983 mortes-503 em Friburgo, 358 em Teresópolis, 95 em Petrópolis, 22 em Sumidouro, 4 em São José do Vale do Rio Preto e 1 em Bom Jardim (não houve mortos em Areal). De acordo com DRM (2011), dentre os movimentos de massa que mais provocaram vítimas fatais e perdas econômicas na Região Serrana destacam-se os fluxos de detritos ao longo do vale do rio Cuiabá (Petrópolis), dos córregos do Vieira e do Príncipe (Teresópolis) e do córrego D'Antas (Nova Friburgo) (Figura 1). 


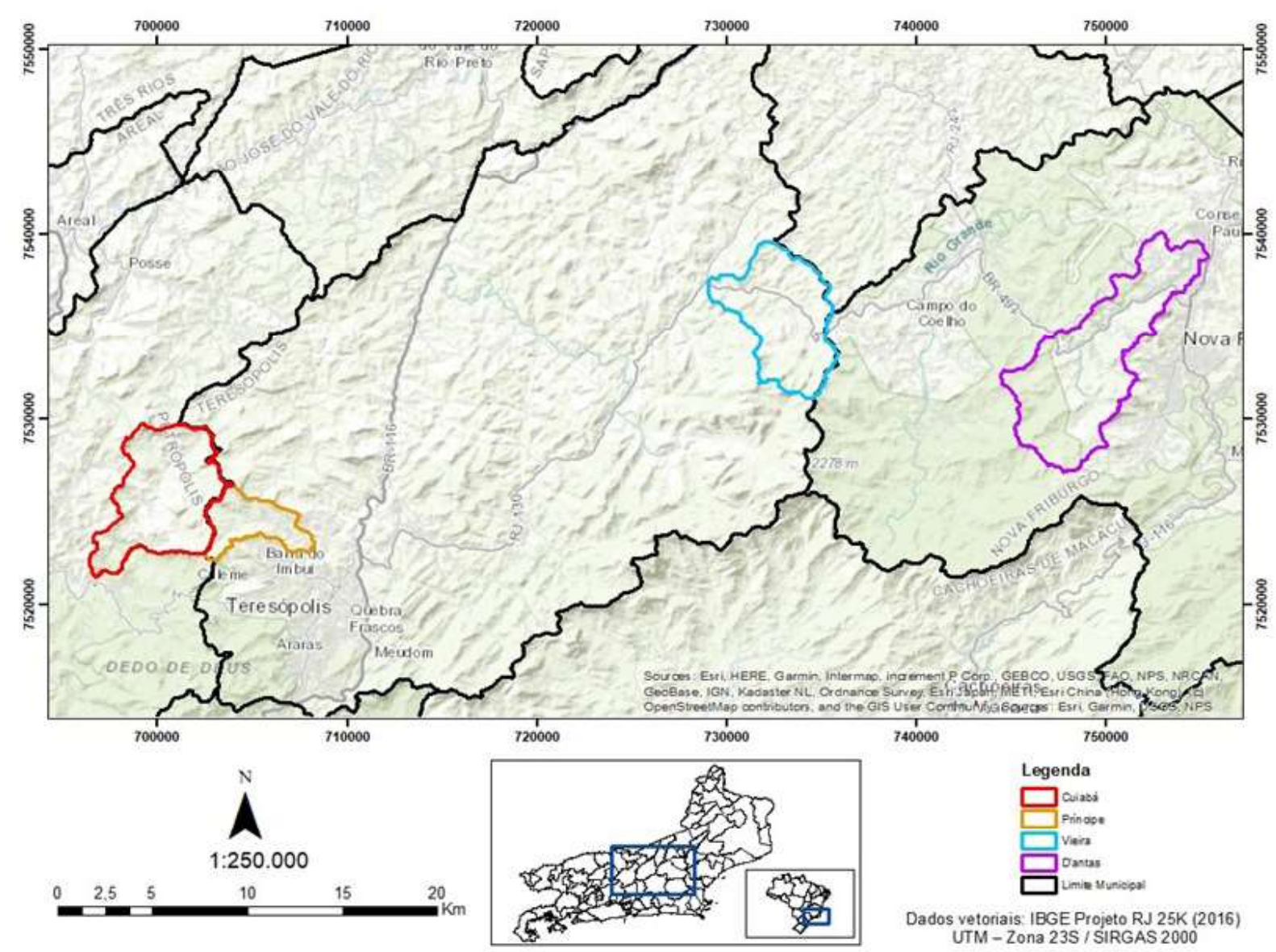

Figura 1 - Mapa de localização das principais bacias atingidas no mega desastre na Região Serrana em 2011.

A serra fluminense é uma das muitas serras que compõem a Serra do Mar, localizada no sudeste do Brasil. A Região Serrana fluminense está localizada no Terreno Oriental da Faixa Ribeira, representado pelo domínio tectônico Costeiro. O Orógeno Ribeira apresenta trend estrutural NE/SW (HEILBRON et al., 2003, 2004). Esta área é constituída por terrenos de paragnaisses meso a neoproterozoicos (Suíte São Fidélis) intrudidos por complexos plutônicos gnaissificados neoproterozoicos (Complexo Rio Negro, Suítes Cordeiro e Serra dos Órgãos) e por granitos da Suíte Nova Friburgo (Figura 2).

O Vale do Cuiabá localiza-se no distrito de Itaipava, norte do município de Petrópolis. A bacia do rio Cuiabá tem altitudes que variam de $740 \mathrm{~m}$ na região da foz a $1.860 \mathrm{~m}$ na região das nascentes. No que diz respeito ao controle estrutural, a direção preferencial do Vale do Cuiabá acompanha nitidamente o forte lineamento NE-SW marcante da região de Itaipava e das variações do curso do rio que estão associadas a lineamentos subordinados na direção NW-SE (vale do Santo Antônio). Várias estruturas rúpteis exibem estas direções na região.
Segundo Melo et al. (2011), o rastro do mega desastre, direção $\mathrm{W}-\mathrm{E} / \mathrm{NE}$, teve início em Itaipava às 00:30 h de 12 de janeiro de 2011. A destruição foi imensa, mas restrita, já que apesar da sua extensão de $9 \mathrm{~km}$ e largura de 20-40 m, o movimento de massa atingiu apenas o Vale do Cuiabá. O cenário, percebido a quilômetros de distância devido ao número de cicatrizes junto à cabeceira do Vale, ficou nítido ao se percorrer o extenso rastro formado pelo fluxo hiperconcentrado (Figura 3A).

Na região norte (Campo Grande, Posse e Cascata do Imbuí) do município de Teresópolis, a bacia do córrego Príncipe foi afetada por fluxos gravitacionais (blocos, solo, lama e água) ao longo dos cursos d'água na madrugada de 12 de janeiro de 2011. O fluxo de detritos do córrego do Príncipe se estendeu por 4,8 km e teve uma largura variando entre 40 e $180 \mathrm{~m}$ (WALDHERR et al., 2011; WALDHERR \& TUPINAMBÁ, 2014; CONQ et al., 2015). O fluxo se desenvolveu a partir de contribuições de material proveniente dos taludes laterais do canal principal, derivados de inúmeros escorregamentos no contato solo-rocha (Figura 3B). 


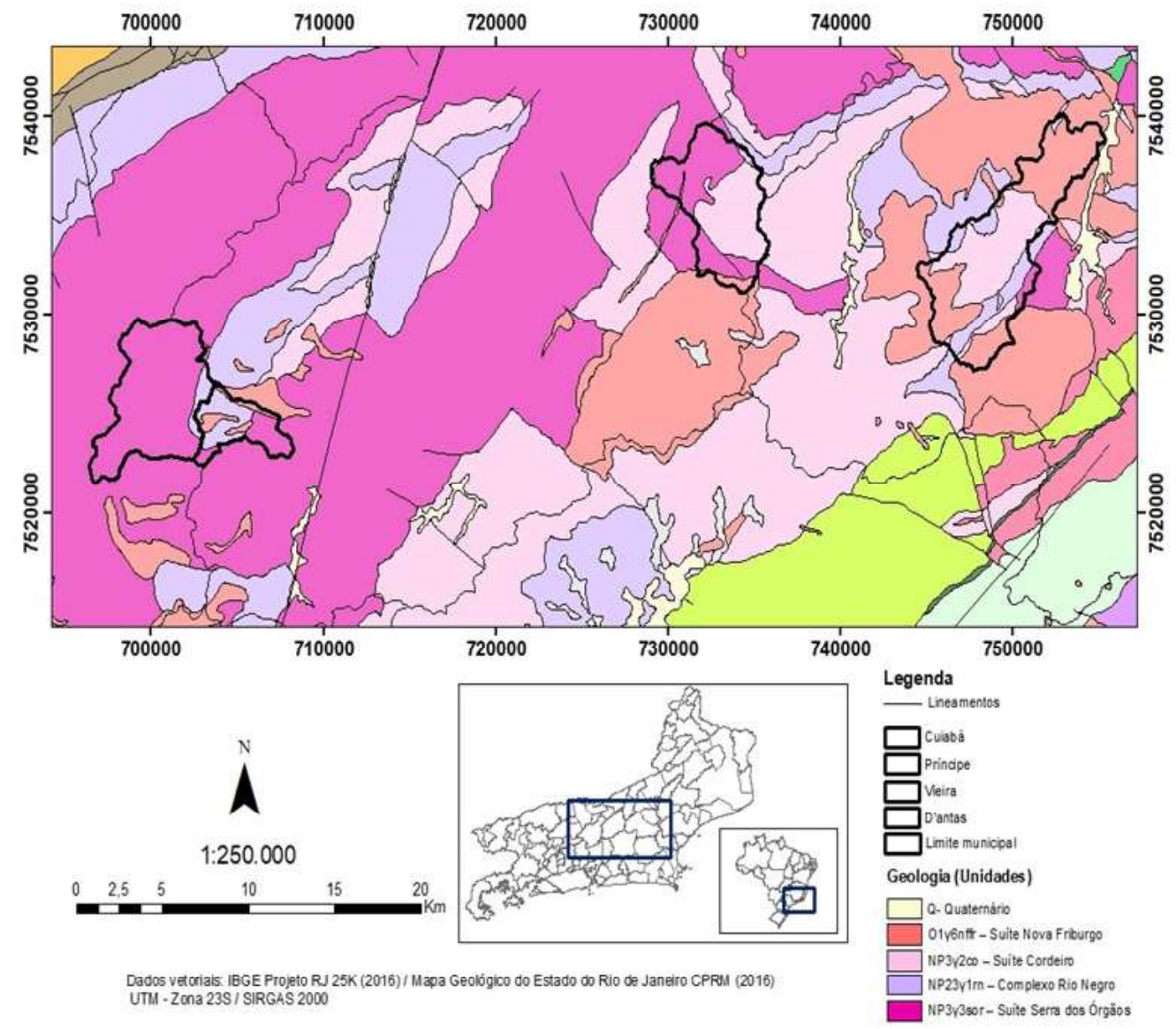

Figura 2 - Recorte do Mapa Geológico da Serra Fluminense do Estado do Rio de Janeiro.

De acordo com Rodrigues et al. (2011) e Lima (2013), a bacia do rio Vieira (Vale de Bonsucesso), município de Teresópolis, foi afetada por um fluxo de detritos, entre as cotas $2.000 \mathrm{~m}$ e $880 \mathrm{~m}$, com alcance de $7,5 \mathrm{~km}$, causando a destruição de centenas de casas e 86 mortes. Na cota $1.440 \mathrm{~m}$, o canal exibe uma mudança em sua direção, passando a ser controlado pelo sistema de fraturas com direção N25W. Esta deflexão abrupta do canal foi responsável pelo barramento temporário do fluxo e uma acumulação provisória de detritos. Após a ruptura, os pulsos de fluxos muito concentrados de detritos mobilizaram blocos rochosos maiores dispostos ao longo do canal. Se o canal principal não exibisse um perfil repleto destas deflexões e "gargantas naturais", a situação possivelmente teria se limitado a um fluxo hiperconcentrado de detritos. No entanto, vencidas as barragens naturais, a massa heterogênea assumiu um caráter absoluto de um fluxo de detritos complexo e destrutivo (Rodrigues et al., 2011; Rodrigues et al., 2012). O fluxo veloz encontrou, contudo, um limite perfeito para seu amortecimento em um campo de futebol localizado à margem do canal principal. Este campo serviu para o depósito dos blocos rochosos que seguiam à frente do fluxo de massa detrítica, retirando do fluxo seu principal elemento de perigo e destruição, uma vez que a partir daquele ponto não havia mais como mobilizar matacões rochosos (Figura 3C). No trecho do canal, cota $1.200 \mathrm{~m}$, na ausência de confinamento lateral, o fluxo percorreu ainda $5 \mathrm{~km}$, passando pelo Hotel São Moritz até chegar ao Restaurante Linguiça do Padre, na cota 900 m, onde afunilou em um knickpoint e passou a ter características propriamente de fluxo de água (Lima, 2013).

Na região centro-norte de Nova Friburgo - córrego D'Antas e rio Bengalas-predominaram os escorregamentos rasos e fluxo de detritos que afetaram o canal principal de drenagem, desde a sua nascente na cota $1.021 \mathrm{~m}$ até a sua confluência com o rio Bengalas na cota $850 \mathrm{~m}$, com $11 \mathrm{~km}$ de extensão e largura máxima de $100 \mathrm{~m}$. Este fluxo causou a destruição de centenas de casas e provocou a morte de 50 pessoas. Segundo Pinto et al. (2011), a corrida de massa do córrego D'Antas recebeu a contribuição de material deslizado oriundo 
de inúmeros escorregamentos (escorregamentos rasos e planares no contato do solo residual com a superfície de rocha sã) ocorridos ao longo da bacia de drenagem e, principalmente, junto a sua cabeceira (Figura 3D). Ao ganhar densidade e viscosidade com este aporte de material, o fluxo de massa ao longo do canal passou a erodir a base dos taludes laterais. No início da chuva, entretanto, grande parte do material da corrida ainda ficou retida nas zonas de estrangulamento do canal do córrego principal, formando grandes lagos nos alvéolos.
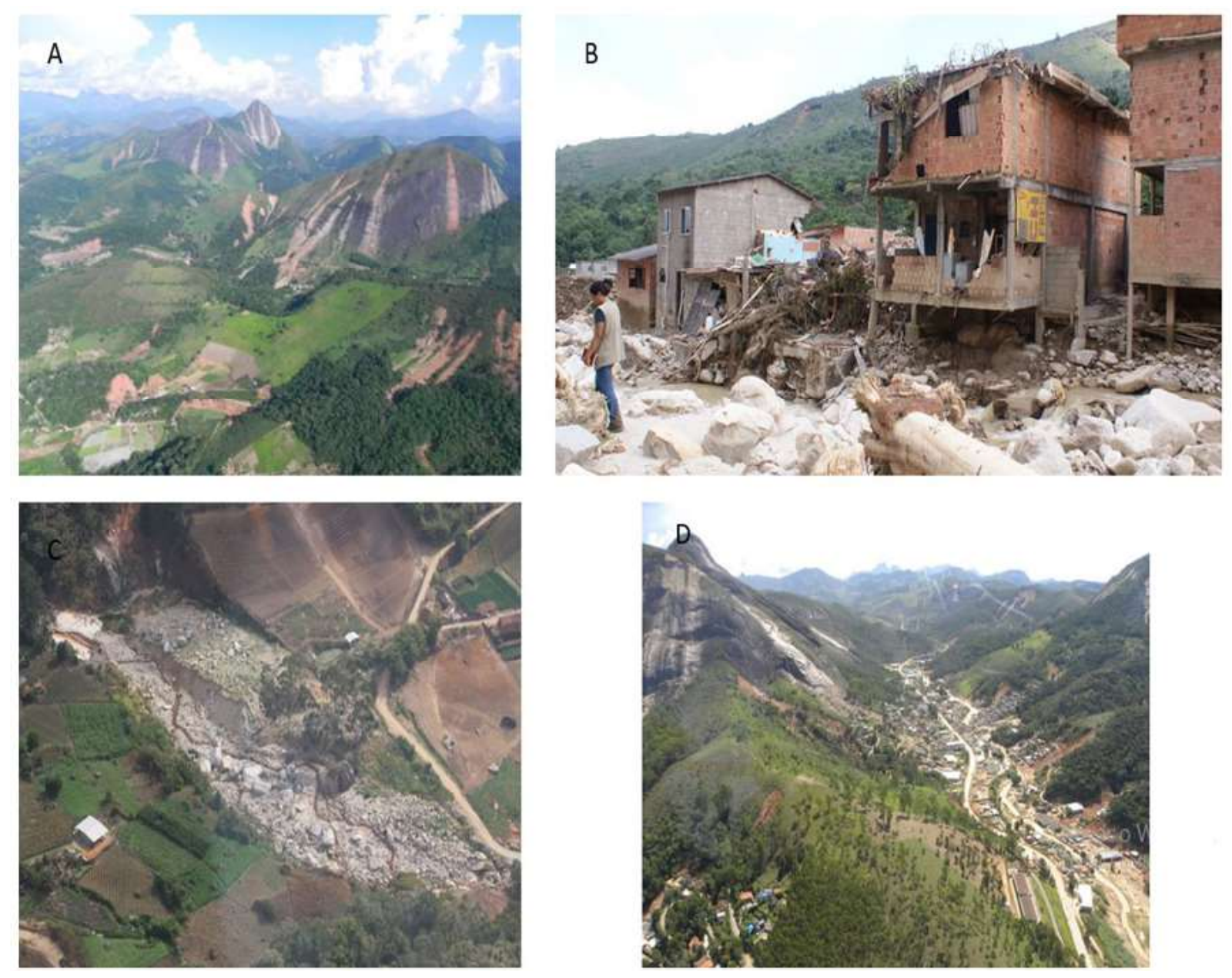

Figura 3 - (A) Escorregamentos rasos ao longo do vale do rio Cuiabá. Fonte: Acervo fotográfico do DRM; (B) Blocos exumados após a passagem do fluxo de detritos. Fonte: Autor; (C) Frente do fluxo de detritos depositada em um antigo campo de futebol no vale do rio Vieira em 2011. Fonte: Autor; (D) Fluxo de detritos ao longo do córrego D'Antas. Fonte: Acervo fotográfico do DRM.

\section{Materiais e Métodos}

\subsection{Aquisição e construção da base de dados}

O mega desastre de 2011 da Região Serrana criou oportunidades excelentes para o estudo dos fluxos de detritos. Com efeitos erosivos e deposicionais, acompanhados dos processos de inundação, a ocorrência dos fluxos de detritos impressionou pela abrangência e dimensão, inclusive com alguns deles exibindo feições de retrabalhamento e mobilização de paleodepósitos. Esta realidade permitiu a seleção das principais bacias afetadas pelo processo geológico na região.

Após a definição da área de estudo, foi realizado o aproveitamento de documentos básicos já disponíveis: cartas topográficas, ortofotos, publicações e acervo fotográfico (Tabela 1). A base de dados foi desenvolvida com apoio do Sistema de Informação Geográfica, software ArcGIS 10.4.1 e SAGA GIS, em estrutura vetorial e matricial. A aquisição e construção da base de dados cartográficos baseou-se em: digitalização, vetorização e edição da informação cartográfica pré-existente. 
Tabela 1: Dados e os mapas derivados.

\begin{tabular}{c|c|c|c}
\hline Dados & Fonte & $\begin{array}{c}\text { Escala ou resolução } \\
\text { original }\end{array}$ & Temas criados \\
\hline $\begin{array}{c}\text { Base topográfica do Projeto } \\
\text { Rio de Janeiro 25k }\end{array}$ & IBGE, ano 2016 & $1: 25.000$ & $\begin{array}{c}\text { Elevação, Ângulo de encosta, } \\
\text { área de contribuição }\end{array}$ \\
\hline $\begin{array}{c}\text { Imagens de satélite stereo } \\
\text { WorldView-2, pós-Mega } \\
\text { desastre de 2011 }\end{array}$ & $\begin{array}{c}\text { Projeto GEORISCO, } \\
\text { ano 2012 }\end{array}$ & $1: 10.000$ & $\begin{array}{c}\text { Feições de escorregamentos e } \\
\text { fluxo de detritos }\end{array}$ \\
\hline $\begin{array}{c}\text { Acervo fotográfico } \\
\text { (fotos oblíquas de } \\
\text { helicóptero) }\end{array}$ & $\begin{array}{c}\text { Serviço Geológico } \\
\text { do Estado do Rio } \\
\text { de Janeiro (DRM), } \\
2011-2014\end{array}$ & $\sim 1: 2.000$ & $\begin{array}{c}\text { Feições de escorregamentos e } \\
\text { fluxo de detritos }\end{array}$ \\
\hline
\end{tabular}

\subsection{Geração do MDT}

Embora muitos trabalhos sobre o impacto do tamanho do pixel na modelagem geográfica tenham sido publicados, a seleção do tamanho da célula (resolução) raramente se baseia na variabilidade espacial inerente dos dados. De fato, na maioria dos projetos de SIG, a resolução do grid é selecionada sem qualquer justificativa científica. A etapa de definição da resolução do MDT foi baseada nas recomendações de Hengl (2006).

De acordo com a definição de Vink (1975), a Delineação Mínima Legível (DML; Minimum Legible Delineation) e a Acurácia Máxima Local (AML; Maximum Location Accuracy ou Average Size Area) podem ser estimadas com base na menor área a ser mapeada. A DMLé referenciada como $2,5 \mathrm{~mm}$ no mapa enquanto a AML indica os valores mínimos de $0,25 \mathrm{~mm}$ a $0,1 \mathrm{~mm}$ e resulta em resoluções mais finas referentes à menor área discernível num mapa. Como valor intermediário, Hengl (2006) sugere a utilização de $0,5 \mathrm{~mm}$ como referência para determinação do tamanho da célula. A Equação 1 indica essa proposta cartográfica de definição do tamanho da célula:

$$
\begin{aligned}
& \mathrm{R}=\mathrm{DE} \times \text { Valor Numérico }= \\
& 25.000 \times 0,0005 \mathrm{~m}=12,5 \mathrm{~m}
\end{aligned}
$$

Equação (1)

onde R é a Resolução da célula, em metros, DE é o Denominador da escala (adimensional) e o Valor numérico (já convertido em metros) se refere ao valor pretendido para a DML ou AML.

Os MDTs com resolução de 12,5 m foram criados a partir de curvas de nível com equidistância de $10 \mathrm{~m}$ e escala de 1:25.000 contidas na base topográfica do Projeto RJ-25, do mapeamento sistemático brasileiro realizado pelo Instituto Brasileiro de Geografia e Estatística (IBGE). O método de interpolação utilizado foi TOPOGRID implementado no software ArcGIS 10.4.1 por meio da ferramenta TopoToRaster (ESRI, 2010). A etapa seguinte foi a remoção das depressões do MDT, utilizando o comando Fill do software ArcGIS 10.4.1. A eliminação das depressões é obrigatória na utilização de modelos que demandam como entrada parâmetros como, por exemplo, área de contribuição a montante de um determinado pixel.

\subsection{Identificação dos fluxos de detritos}

A delimitação da área fonte nas encostas e dos depósitos das corridas de detritos foi feita utilizando-se a imagem de satélite WorldView-2 (obtida em 2012; escala 1:10.000) do acervo de fotos de helicóptero tomadas pelo Serviço Geológico do Estado do Rio de Janeiro (DRM-RJ) e de investigações de campo. A identificação e o mapeamento do processo geomorfológico foram pautados na análise visual sobre as imagens, considerando os seguintes aspectos: a tonalidade, pois reflete os locais onde ocorreram estes processos; o tamanho, pois corresponde à extensão e dimensão da área afetada; e a posição topográfica deste processo. As 918 cicatrizes de escorregamentos foram classificadas de acordo com a posição e mobilidade dos detritos (Figura 4), baseado em Imaizumi et al. (2006): (i) escorregamentos atingindo o canal (tipo A); escorregamento terminando na encosta (tipo B); (iii) escorregamento que imediatamente termina no canal de drenagem (tipo A1); e (iv) escorregamento que movimenta encosta abaixo com um fluxo de detritos (tipo A2). 


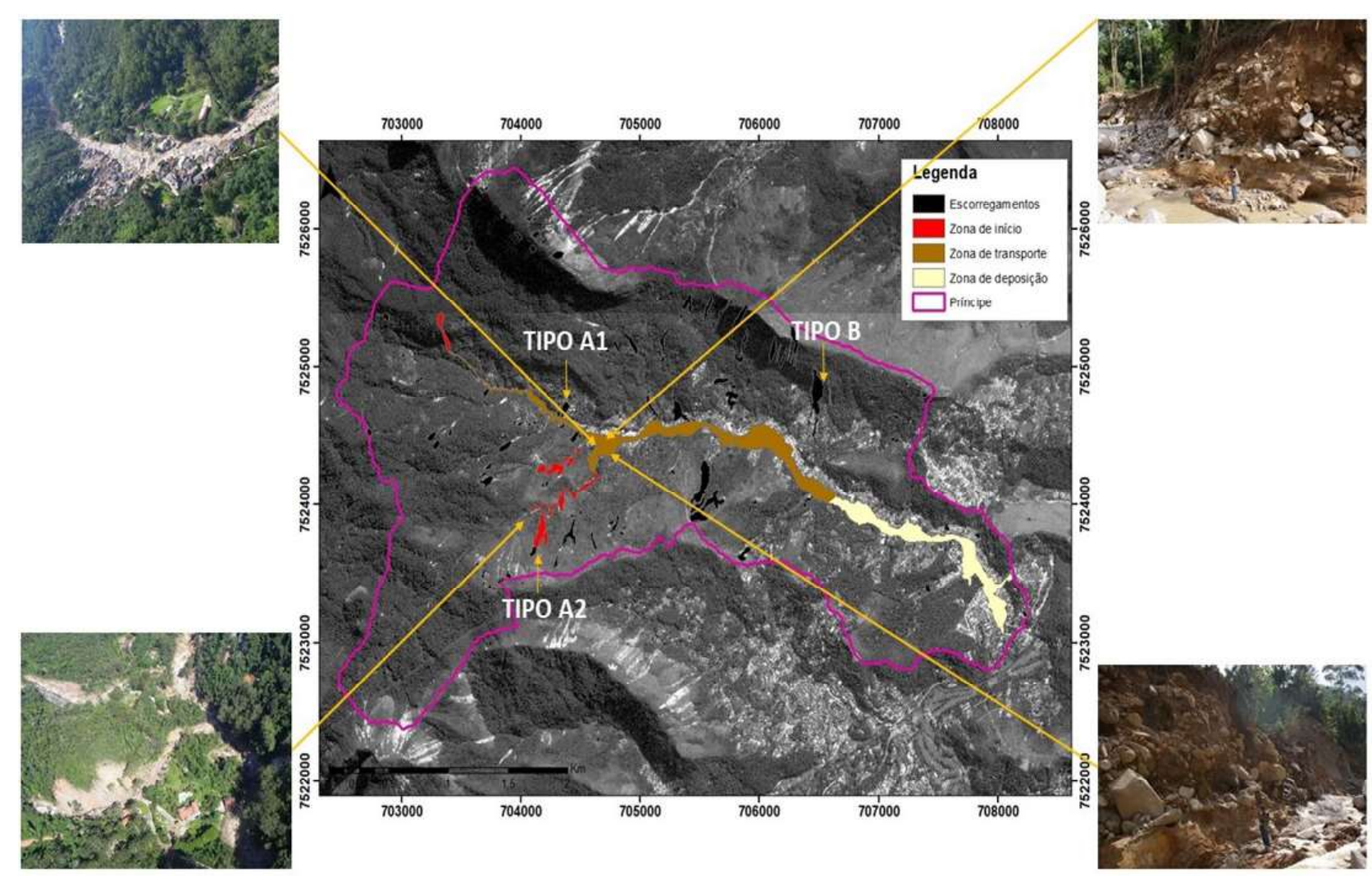

Figura 4 - Mapa de localização das cicatrizes de escorregamentos e fluxo de detritos da bacia do Príncipe. Baseado em Imaizumi et al. (2006): Escorregamento que imediatamente termina no canal de drenagem (tipo A1); Escorregamento que movimenta encosta abaixo como um fluxo de detritos (tipo A2); Escorregamento terminando na encosta (tipo B).

As correções de campo foram realizadas com auxílio fotográfico obtido desde helicópteros e terrestres e permitiram corroborar as informações sobre os fluxos de detritos por meio do papel desempenhado pela geologia, pelas estruturas, pelos perfis de alteração, pelos depósitos pretéritos e atuais e pela distância de atingimento, considerando a morfometria da bacia (Figura 5). O mapeamento das rupturas e zonas de acumulações dos fluxos de detritos foi constante dentro de uma bacia hidrográfica.

\subsection{Determinação dos índices morfométricos}

Nos últimos 35 anos, índices morfométricos têm sido amplamente utilizados para a avaliação de escorregamentos e fluxos de detritos em diferentes ambientes geomorfológicos no mundo (JACKSON et al., 1987; RICKENMANN \& ZIMMERMAN, 1993; JAKOB, 1996; MIZUHARA, 1996; BOVIS \& JAKOB, 1999; DE SCALLY et al., 2001; WELSH, 2008; CHEN \& YU, 2011; CONFORTI et al., 2011; WELSH \& DAVIES, 2011; ROGELIS \& WERNER, 2014; VIEIRA et al., 2019). Por outro lado, estudos mais recentes de análise de índices morfométricos para o entendimento da dinâmica dos fluxos de detritos passaram a priorizar o uso de métodos objetivos visando facilitar e agilizar a análise. A Tabela 2 resume as variáveis morfométricas identificadas na literatura que podem contribuir para a caracterização de fluxos de detritos.

Índices morfométricos de grande importância para caracterizar os fluxos de detritos foram selecionados com base na literatura. Dessa forma, com apoio nos trabalhos De Scally et al. (2001), Chen e Yu (2011), Conforti et al. (2011) e Rogelis e Werner (2014), a partir do MDT, foram extraídos os seguintes índices: Ângulo de Encosta, Índice Topográfico de Umidade (ITU), LS e IPUC.

O Ângulo de Encosta é considerado um dos fatores predisponentes com maior influência na ocorrência de fluxos de detritos. A ampla variação no limite inferior de ângulos de encostas conhecidos por deflagrar os fluxos de detritos $\left(20^{\circ}-67,5^{\circ}\right)$ mostra claramente que outros fatores geomórficos, hidrológicos, geológicos e pedológicos são determinantes para a estabilidade da encosta (SIDLE \& OCHIAI, 2006). 

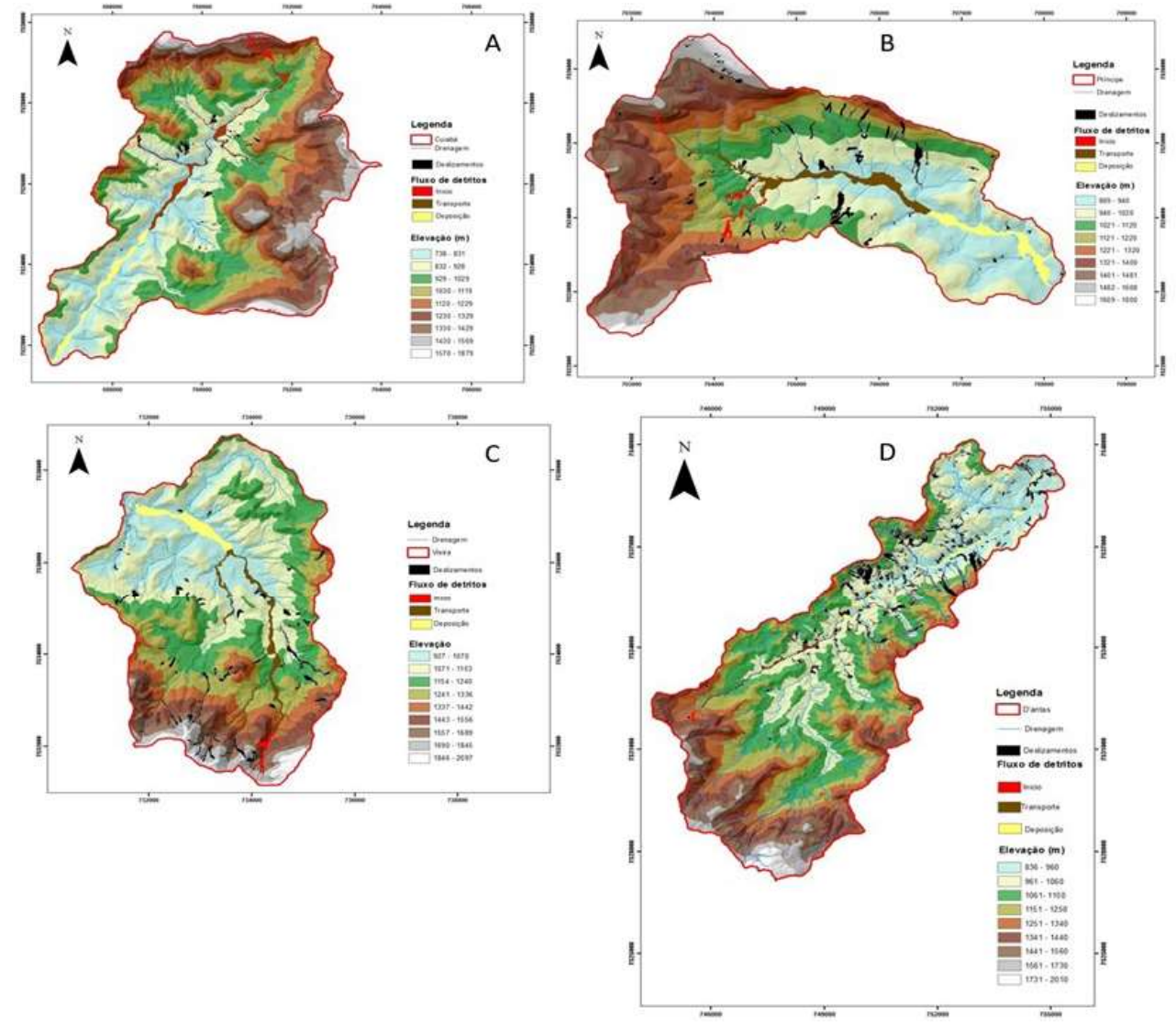

Figura 5 - Delimitação dos escorregamento e fluxos de detritos baseado em Modelos Digitais do Terreno para as bacias de (A) Cuiabá, (B) Principe, (C) Vieira e (D) D'Antas, mega desastre da Serra de 2011.

Tabela 2: Principais índices morfométricos de bacias de drenagem empregados na análise de fluxos de detritos.

\begin{tabular}{|c|c|c|}
\hline Morfometria & Conceito & Relevância e citações \\
\hline Fator de Forma & 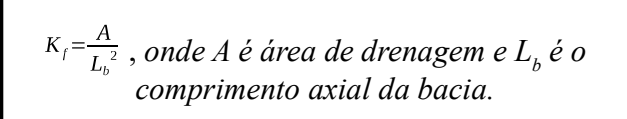 & $\begin{array}{l}\text { Relacionado ao fluxo de pico e à ocorrência do fluxo de } \\
\text { detritos (CHEN et al., 2014). }\end{array}$ \\
\hline $\begin{array}{l}\text { Índice de } \\
\text { Circularidade }\end{array}$ & $\begin{array}{l}I_{\mathrm{c}}=12.57 \times \frac{A}{P^{2}} \quad \text { e } I_{c}=\frac{A}{A_{c}} \\
\text { onde A é a área da bacia }\left(\mathrm{km}^{2}\right) \text { e } A_{c} \text { é a área do } \\
\text { círculo de mesmo perímetro }(\mathrm{km}) .\end{array}$ & $\begin{array}{l}\text { Expressa o quanto a bacia se aproxima da forma circular, } \\
\text { determinando o tempo de concentração (AUGUSTO FILHO, } \\
\text { 1993; RICKENMANN \& ZIMMERMANN, 1993). }\end{array}$ \\
\hline Relação de Relevo & $\begin{array}{c}R_{r}=\left(\frac{H_{m}}{L_{b}}\right), \\
\text { onde } H_{m} \text { é amplitude altimétrica e } L_{b} \dot{e} \\
\text { comprimento axial da bacia. }\end{array}$ & $\begin{array}{l}\text { Usado para descrever a distância de viagem de fluxo } \\
\text { de detritos e a magnitude do evento (JAKOB, 1996; } \\
\text { WILFORD et al., 2004; CHEN et al., 2014). }\end{array}$ \\
\hline Índice de Melton & $\begin{array}{c}R=H_{m} / \sqrt{A} \text {, onde } H_{m} \text { é amplitude altimétrica e } A \text { é } \\
\text { a área total da bacia. }\end{array}$ & $\begin{array}{l}\text { Frequentemente usado para discriminar entre processos } \\
\text { geohidromórficos (JACKSON et al., 1987; BOVIS \& JAKOB, } \\
\text { 1999; WILFORD et al., 2004; WELSH \& DAVIES, 2011; } \\
\text { BERTRAND, 2014; CORSI et al., 2015; FERREIRA et al., } \\
\text { 2016; PICANÇO et al., 2016). }\end{array}$ \\
\hline $\begin{array}{l}\text { Índice Topográfico de } \\
\text { Umidade }\end{array}$ & $\begin{array}{l}I T U=\ln \left(\frac{A s}{\tan \alpha}\right), \text { onde } A_{s} \text { é a área de drenagem especí-fica } \\
\text { por unidade de contorno e } \alpha \text { é o ângulo de encosta. }\end{array}$ & $\begin{array}{l}\text { Demonstra o efeito do relevo na localização e tamanho das } \\
\text { zonas de saturação (CHEN \& YU, 2011). }\end{array}$ \\
\hline $\begin{array}{l}\text { Índice de Potência } \\
\text { Unitária de Corrente }\end{array}$ & $\begin{array}{l}\text { IPUC }=\text { As } x \tan \alpha, \text { onde } A_{s} \text { é a área de drenagem } \\
\text { específica por unidade de contorno e } \alpha \text { é o ângulo } \\
\text { de encosta }\end{array}$ & $\begin{array}{l}\text { Demonstra o efeito da erosão fluvial } \\
\text { (CHEN \& YU, 2011). }\end{array}$ \\
\hline Fator topográfico & $\begin{array}{l}L S=\left(\frac{A s}{22.13}\right)^{n}\left(\frac{\sin \alpha}{0.0896}\right)^{m}, \text { onde } A_{s} \text { é a área de drenagem } \\
\text { específica por unidade de contorno, } \alpha \text { é a ângulo de } \\
\text { encosta e } n \text { e } m \text { são constantes. }\end{array}$ & $\begin{array}{l}\text { Explica os efeitos da topografia tanto no transporte de } \\
\text { sedimentos como na erosão (CHEN \& YU, 2011). }\end{array}$ \\
\hline
\end{tabular}


A propagação e deposição de fluxos de detritos é resultado de condições específicas, incluindo diminuição da inclinação, perda do confinamento e impossibilidade de continuidade do movimento com a interrupção do fluxo. Estas condições podem ocorrer de forma isolada ou conjunta, dependendo da magnitude do movimento e características geométricas da encosta. $\mathrm{O}$ leque de deposição, normalmente, se torna uma zona de perigo na qual desastres associados a fluxos de detritos frequentemente são observados em declives inferiores a $10^{\circ}$ (HUNGR et al., 2013).

O mapa de Ângulo de Encosta foi obtido utilizando o algoritmo proposto por Zevenbergen e Thorne (1987) no SAGA GIS, por meio da ferramenta "Slope, Aspect, Curvature". Esta ferramenta permite a geração do mapa de Ângulo de Encosta, Aspecto e Curvatura, tomando como entrada o MDT. A saída pode ser definida em radianos, grau e porcentagem. O mapa Ângulo de Encosta foi definido em graus.

O ITU combina a área de contribuição a montante de uma determinada célula com o declive dessa mesma célula, o que descreve a sua tendência em acumular água. Este índice é definido pela Equação 2:

$$
I T U=\ln \left(\frac{A_{s}}{\tan \beta}\right)
$$

Equação (2)

onde $A_{s}$ é a área de contribuição específica e $\beta$ é o ângulo de encosta (BEVEN \& KIRKBY, 1979). O ITU é utilizado para demonstrar o efeito do relevo na localização e tamanho das zonas de saturação.

No presente trabalho, o mapa de ITU (Topographic Wetness Index) foi obtido utilizando o software SAGA GIS (BEVEN \& KIRKBY, 1979; MOORE et al., 1991; BOEHNER \& SELIGE, 2006). Enquanto o ArcGIS 10.4.1 considera um único algoritmo de distribuição de fluxo (fluxo unidimensional), o Deterministic 8 (D8) (O'CALLAGHAN \& MARK, 1984), o SAGA GIS é muito mais evoluído neste aspecto, apresentando inúmeras opções de algoritmos de distribuição de fluxo, tais como D8, Braunschweiger Reliefmodell, Rho 8, Multiple Flow Direction (MFD), Deterministic Infinity (Dinf), Triangular Multiple Flow Direction (TMFD) e Multiple Flow Direction based on Maximum Downslope Gradient (MFD-md). Para gerar o ITU, também é necessário calcular o mapa de Ângulo de Encosta. Neste caso, é importante deixar a unidade de saída em radianos; caso contrário, erros no cálculo do ITU poderão ocorrer. Desta forma, o ITU é calculado usando as seguintes ferramentas em sequência: Acumulação de Fluxo (Flow Accumulation - TOPDOWN - Multiple Flow Direction) $<$ Flow Width and Specific Catchment Area proposto por Quinn et al. (1991) < Topographic Wetness Index (TWI).

Chen e Lee (2010) analisaram os valores médios de ITU das áreas fonte de corrida em 11 bacias hidrográficas em Taiwan. Para as bacias estudadas, as corridas de detritos originaram-se por escorregamentos translacionais na condição de alto ITU ou altos valores de Ângulo de Encosta.

O IPUC (Stream Power Index) fornece uma correlação entre os caminhos de fluxo de água, as acumulações de fluxo e o ângulo de encosta que, juntos, definem o potencial de energia que a superfície da água tem para a erosão. Este índice é definido pela Equação 3:

$$
I P U C=A_{s} x \tan \beta \quad \text { Equação (3) }
$$

onde $A_{s}$ é a área de contribuição específica e $\beta$ é o ângulo de encosta (MOORE et al., 1991). O mapa do IPUC (Stream Power Index) foi calculado utilizando o raster calculator no ArcGIS 10.4.1, tendo como entrada os mapas de área de contribuição e ângulo de encosta (em graus radianos).

Chen e Wang (2017) estudaram as mudanças nas características topográficas da bacia do rio Chenyoulan, Cidade Nantou, Taiwan, afetada por fluxos de detritos entre 1996 e 2004. Os resultados mostram que o IPUC e o pico de descarga na bacia aumentaram após a recorrência do fluxo de detritos. O ITU indicou maior potencial de escorregamento quando a inclinação da bacia era mais acentuada.

A grande maioria dos trabalhos que aplicaram o IPUC para predizer áreas suscetíveis a corridas de detritos encontraram altos valores de aumento da probabilidade de fluxos de detritos (CHEN \& YU, 2011).

Araújo (2012) aplicou ITU e IPUC na bacia D’Antas, Nova Friburgo. Os valores mais elevados de potencial de escorregamento foram obtidos para as classes menos representativas (baixa frequência) do ITU. Destaca-se a classe $(14,32-16,66)$, que apresenta potencial de escorregamento de 28,02\%. Entretanto, segundo o autor, estes resultados podem estar comprometidos pelo mapeamento das áreas de depósito dos escorregamentos, 
alcançando os setores mais saturados da bacia, próximos ao canal de drenagem ou da planície de inundação.

Já para o IPUC, apesar de haver um elevado potencial de fluxo de detritos associado às áreas onde os valores de IPUC também são elevados, o autor não identificou a fase da corrida relacionada a este potencial. O entendimento do comportamento do processo, analisado pelo IPUC, demanda o mapeamento das zonas de origem, transporte e deposição. Segundo o autor, por meio da identificação destas zonas ao longo da corrida de detritos, valores limites do IPUC poderão ser obtidos para cada uma das fases do processo.

O LS (LS Factor) explica os efeitos da topografia tanto no transporte de sedimentos como na erosão. $\mathrm{O}$ fator-L e o fator-S são geralmente considerados juntos para combinar o efeito de Comprimento da Rampa e Declividade, que basicamente reflete o terreno em um determinado local. Combinando os resultados de Zingg (1940), Musgrave (1947), Smith e Whitt (1948) e Wischmeier e Smith (1965), obtém-se a seguinte expressão para LS (Equação 4):

$$
L S=\left(\frac{A s}{22.13}\right)^{n}\left(\frac{\operatorname{sen} \beta}{0.0896}\right)^{m}
$$

Equação (4)

A equação que representa a influência do terreno na erosão do solo pode então ser reescrita em forma adimensional, de modo que o índice LS se torne unidade para o caso quando for área de contribuição a montante $=$ 22,13 e a inclinação for $9 \%$, o qual é o fator LS baseado no poder unitário da corrente proposto por Moore e Burch (1986). Foi demonstrado que os valores de $\mathrm{m}=0,6 \mathrm{e} \mathrm{n}=$ 1,3 dão resultados consistentes com o LS da RUSLE para os comprimentos de vertente $\lambda<100 \mathrm{~m}$ e os ângulos de inclinação $\beta<14^{\circ}$ (MOORE \& WILSON, 1992).

O fator comprimento da vertente (L) tem como fundamentação teórica o método de Foster et al. (1977) expresso na Equação 5:

$$
L=\left(\frac{\lambda}{22.13}\right)^{m} \quad m=\frac{F}{1+F} \quad F=\frac{\operatorname{sen} \beta / 0.0896}{3(\operatorname{sen} \beta)^{0,8}+0.56}
$$

Equação (5)

onde $\lambda$ é um valor intermediário, $m$ é um parâmetro que depende de $\beta$, e $\beta$ é o ângulo que tem no local do run-off.
Assim $\lambda$ é determinado como sendo o comprimento de uma seção de análise. O desenvolvimento dos Sistemas de Informações Geográficas viabilizou a aplicação da Equação Universal de Perda do Solo Revisada. Desmet e Gover (1996) desenvolveram um algoritmo que emprega o conceito de área de contribuição, contendo em sua formulação o fluxo acumulado conforme a Equação 6:

$$
L_{i, j}=\frac{\left[\left(A_{i, j-i}+D^{2}\right)^{m+1}-\left(A_{i, j-i}\right)^{m+1}\right]}{\left[D^{m+2} x_{i, j-i}{ }^{m}(22.13)^{m}\right]}
$$

Equação (6)

onde $L_{i, j}$ é o fator de comprimento de vertente de uma célula com coordenadas (i,j), $A_{i, j-\zeta}$ é a área de contribuição de uma célula com coordenadas $(\mathrm{i}, \mathrm{j})\left(\mathrm{m}^{2}\right)$, $\mathrm{D}$ é o tamanho da grade de células $(\mathrm{m}), x_{i, j-i}$ é o valor da direção do fluxo, e $m$ é o coeficiente que assume os valores 0.5 (se $\mathrm{s} \geq 5 \%$; s é o grau de declividade), 0.4 (se $3 \% \leq \mathrm{s}<3 \%$ ) ou 0.2 (se $\mathrm{s}<1 \%$ ).

O cálculo do fator declividade da vertente (S) proposto por McCool et al. (1987) é em função da inclinação. Logo, quando a tangente da inclinação é menor que 10.09, utiliza-se a Equação 7:

$$
S_{(i, j)}=10.08 \operatorname{sen} \beta_{(i, j)}+0.03 \quad(\mathrm{~S}<9 \%) \quad \text { Equação (7) }
$$

Quando esta condição é cumprida, utiliza-se a Equação 8:

$$
S_{(i, j)}=16.8 \operatorname{sem} \beta_{(i, j)}-0.5 \quad(\mathrm{~S} \geq 9 \%) \quad \text { Equação }(8)
$$

Desmete Govers (1996) provaram que este modelo de LS é apropriado para a modelagem de erosão do solo em escala de paisagem e pode capturar topografia complexa. O mapa de LS (LS Factor) foi obtido utilizando o método proposto por Desmet e Gover (1996) no software SAGA GIS. LS foi calculado usando um dos módulos de hidrologia disponíveis no SAGA $(L S$ -factor) que incorpora o algoritmo de fluxo múltiplo (PILESJÖ \& HASAN, 2014).

Tunusluoglu et al. (2007) mostraram que os valores médios de LS das áreas fontes de fluxo de detritos $(9,4)$ têm expressiva diferença em relação aos valores das áreas que não são fontes de fluxo de detritos $(3,85)$, indicando que LS pode ser um parâmetro útil na diferenciação de fontes de fluxos de detritos. 


\subsection{Aplicação do método estatístico}

No presente trabalho foram utilizados os seguintes fatores: Ângulo de Encosta, ITU, IPUC e LS. A variável dependente diz respeito às áreas de fluxo de detritos. Assim, atribui-se o valor " 1 " para os polígonos representativos das áreas afetadas pelas corridas. A feição de polígono foi adotada a partir do levantamento descrito no item 3.3 para uma melhor representação física das zonas de início, transporte e deposição. Utilizando a função Combine no ArcGIS 10.4.1, estes polígonos foram multiplicados por cada um dos mapas temáticos e, como resultado, os novos polígonos gerados passaram a conservar os valores dos atributos dos mapas temáticos.

Posteriormente, foi analisada a Razão de Frequência (RF, Frequency Ratio), fundamentada na relação entre a porcentagem de ocorrências cartografadas dentro de uma determinada classe e a percentagem que essa classe ocupa dentro da área de estudo (BONHAM-CARTER, 1994). Logo, valores de RF maiores que uma unidade estabelecem forte afinidade entre as variáveis dependentes (fluxo de detritos) e as explicativas (índices topográficos); em contrapartida, valores inferiores a essa unidade inferem uma baixa relação de atrelamento entre ambas as variáveis (LEE \& TALIB, 2005; ANGILLIERI, 2013).

RF pode ser calculada de acordo com a Equação 9:

$$
R F=\frac{S_{i j}}{S} / \frac{N_{i j}}{N}
$$

Equação (9)

onde $\mathrm{N}$ é o espaço total que está sendo investigado, $\mathrm{S}$ é o número de pixels com ocorrências de fluxo de detritos, $N i j$ é a zona ocupada pela classe i de algum cartograma j, e Sij é a área ocupada pelos fluxos de detritos em $N i j$.

O método do Valor Informativo (VI; YAN, 1988; YIN \& YAN, 1988; VAN WESTEN, 1997; PIEDADE et al., 2011) tem uma base Bayesiana, sustentando-se na transformação logarítmica (log natural) da Razão de Frequência. VI pode ser calculado de acordo com Equação 10:

$$
V I=\ln (R F) \quad \text { Equação (10) }
$$

Com este método foi possível ponderar cada classe de forma objetiva, quantificada e reprodutível, considerando-se os valores positivos de VI relevantes para o desenvolvimento dos fluxos e desprezando-se os valores negativos (YIN \& YAN, 1988; PIEDADE et al., 2011).
Xu et al. (2013) usaram SIG para analisar os VIs de sete fatores ambientais (elevação, declividade, aspecto, área de contribuição, cobertura vegetal, tipo de solo e uso do solo) e determinar a suscetibilidade de fluxo de detritos na província de Sichuan-China. O inventário de fluxo de detritos utilizados nesse estudo foi formato ponto. Os resultados indicaram que os VIs dos solos aluviais, neossolos e solos ácidos são mais altos que os dos outros. O VI máximo de elevação ficou na faixa de 1.750-2.250 m, ângulos de encostas superiores a $45^{\circ}$, cobertura vegetal $40-60 \%$, aspecto Leste-Sul e área de contribuição 150-200.

Melo e Zêzere (2017) desenvolveram uma avaliação da suscetibilidade à ocorrência de fluxos de detritos na bacia hidrográfica do rio Zêzere (a montante da vila de Manteigas-Portugal), considerando separadamente a área de erosão e área de deposição (em formato de polígono). Analisando as potenciais áreas de ruptura, esses autores usaram o método do VI e constataram que as variáveis preditivas com maior relevância na ocorrência de fluxos de detritos correspondem às áreas queimadas (em 2005), ângulos de encosta superiores a $30^{\circ}$, espessura de solo inferior a $75 \mathrm{~cm}$ e perfil transversal côncavo. Para simular a propagação dos fluxos de detritos, esses autores utilizaram o modelo D-infinity downslope influence (DI).

Com base nesses estudos anteriores, para avaliar o comportamento de cada índice topográfico na caracterização dos fluxos de detritos foi adotado o método do VI. Assim, com base no tamanho de célula adotado para os MDTs, a Tabela 3 apresenta o total de células para as áreas de estudos.

Tabela 3: Total de células para as áreas de estudos.

\begin{tabular}{c|c}
\hline Bacia & Total de células (12,5-m) \\
\hline Príncipe & 76.611 \\
\hline Vieira & 162.193 \\
\hline Cuiabá & 230.919 \\
\hline D'Antas & 340.415 \\
\hline
\end{tabular}

\section{Resultados e Discussões}

Análise estatística bivariada foi utilizada na aplicação do método do VI e dos fatores predisponentes Ângulo de Encosta, ITU, IPUC e LS. Valores positivos de VI indicam as condições predisponentes que melhor se aplicam considerando a distribuição espacial das ocorrências dos fluxos de detritos. 
A Figura 6 demonstra o ângulo das encostas das bacias estudadas. A bacia do Cuiabá apresentou predominância de valores superiores a $30^{\circ}(12 \%)$ localizadas majoritariamente ao longo das vertentes do Vale do Cuiabá e Santo Antônio, e a existência de inclinações abaixo de $5^{\circ}(<20 \%)$. O ângulo das encostas da bacia do Príncipe apresentou predominância de valores inferiores a $17^{\circ}(40 \%)$ e a existência muito restrita de inclinações acima de $45^{\circ}(<5 \%)$. Mais de $50 \%$ das encostas da bacia do Vieira estão situadas entre $10^{\circ}$ a $30^{\circ}$ e distribuem-se por toda a região. As encostas acima de $30^{\circ}$ estão restritas em grande parte aos terrenos serranos do sul. O ângulo das encostas da bacia do D'Antas apresentou domínio de ângulos de encosta entre $10^{\circ}$ a $30^{\circ}(60 \%)$.
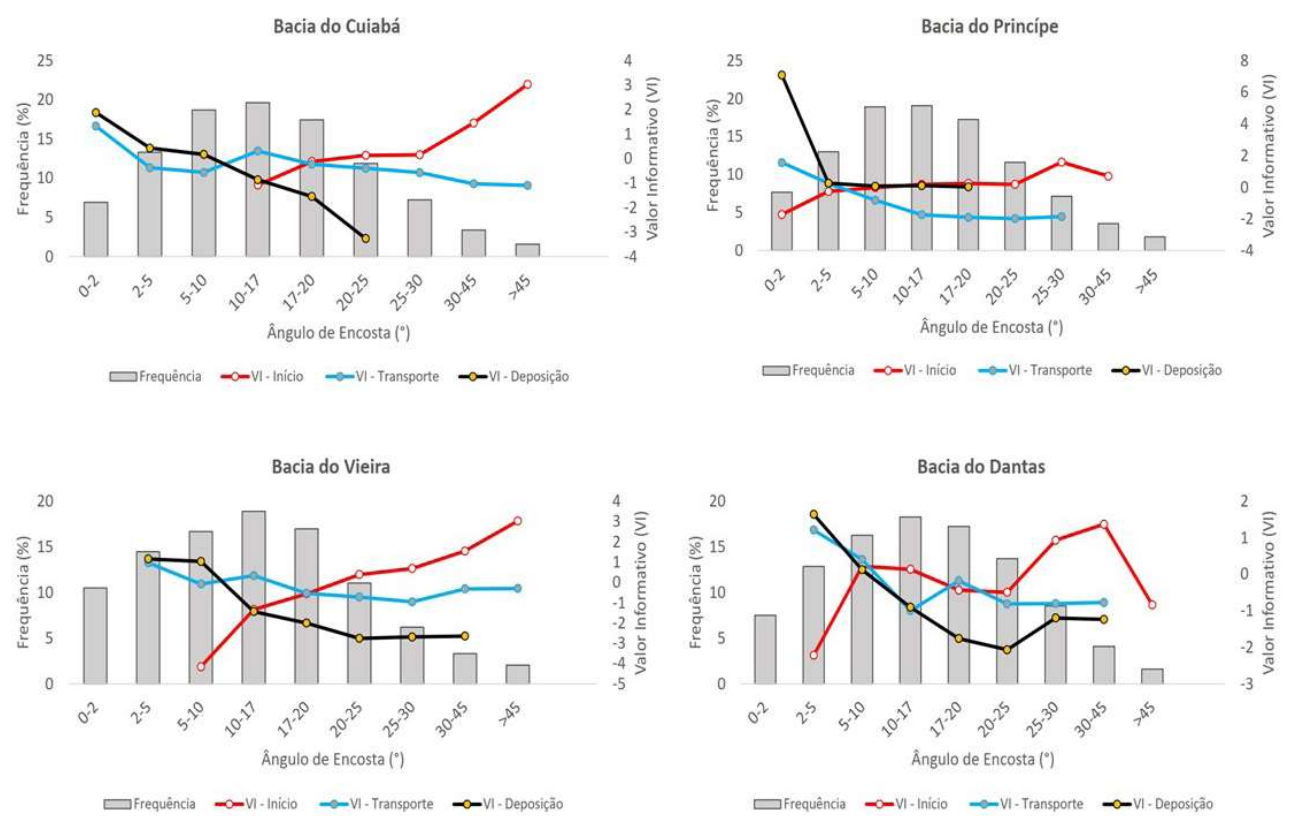

Figura 6 - Aplicação do método do Valor Informativo: Frequência de fluxos de detritos em função dos intervalos de Ângulos de Encosta.

Os resultados indicaram, para todas as bacias, escorregamentos em encosta do Tipo A2, cujo sedimento é transportado como fluxos de detritos através do sistema de canais de drenagem. Pôde-se verificar que os fluxos de detritos foram iniciados a partir de escorregamentos rasos com ângulos de encosta maiores que $45^{\circ}$, que é ligeiramente superior aos valores típicos para áreas fontes de fluxo de detritos encontrados na literatura ( $20^{\circ}-45^{\circ}$, HUNGR, 2005 ; ou $27^{\circ}-38^{\circ}$, RICKENMANN \& ZIMMERMANN, 1993) (Figura 6).

O Brasil também tem sido cenário de vários fluxos de detritos catastróficos, destacando-se dois ambientes muito propícios. O primeiro cenário corresponde à Serra do Mar, que apresenta casos de ocorrência de fluxo de detritos e lama a partir de escorregamentos generalizados registrados na sua história. Para a Serra do Mar, o intervalo entre $30^{\circ}$ e $40^{\circ}$ é apontado como o mais suscetível a escorregamentos rasos (GRAMANI, 2013; NUNES \& SAYÃO, 2014). Por exemplo, Fernandes et al. (2001) identificaram nas bacias do Quitite e
Papagaio, Rio de Janeiro, que foram afetadas por fluxo de detritos no evento de 1996, uma pequena quantidade de cicatrizes de escorregamentos entre $0^{\circ}-18,5^{\circ}$ e o aumento do potencial de escorregamento com o aumento do ângulo de encosta até a classe $37^{\circ}-55.5^{\circ}$. Em outro cenário, na Serra do Mar paranaense, Silveira et al. (2013) identificaram que encostas acima de $30^{\circ}$ associadas a cotas superiores a $400 \mathrm{~m}$ tendem a ser mais suscetíveis a escorregamentos e fluxo de detritos

Observa-se, ainda, que a redução dos valores informativos nos intervalos de ângulos inferiores a $45^{\circ}$ se deve não somente à redução da frequência desses intervalos, mas também à remoção dos materiais por processos erosivos. Segundo Sidle e Ochiai (2006), embora escorregamentos rasos tenham ocorrido em encostas tão íngremes quanto $>70^{\circ}$, a inclinação mais íngreme que $45^{\circ}$ costuma ter uma menor frequência de escorregamentos pelo fato de o manto de solo já ter sido removido pela força gravitacional de massa (mass wasting), deixando mais estável o leito rochoso exposto. 
Segundo Hungr (2005), as zonas de transporte têm inclinação superior a $10^{\circ}$ e podem ter superfície em rocha sã, rocha fraturada, solos, detritos ou outros. O método do VI indicou que a zona de transporte dos fluxos de detritos ocorreu com média de ângulo de encosta de $5^{\circ}$; esse resultado corrobora as análises feitas por YI WU (2003), que reporta a zona de movimento com ângulos de encosta entre $6^{\circ}-15^{\circ}$ na região da Tailândia

A deposição dos fluxos de detritos é resultado de condições específicas, incluindo diminuição da inclinação, perda do confinamento e impossibilidade de continuidade do movimento com a interrupção do fluxo. Estas condições podem ocorrer de forma isolada ou conjunta, dependendo da magnitude do movimento e das características geométricas da encosta. O leque de deposição normalmente se torna uma zona de perigo onde os desastres associados a fluxos de detritos são frequentemente observados (JAKOB, 1996; HUNGR et al., 2013).
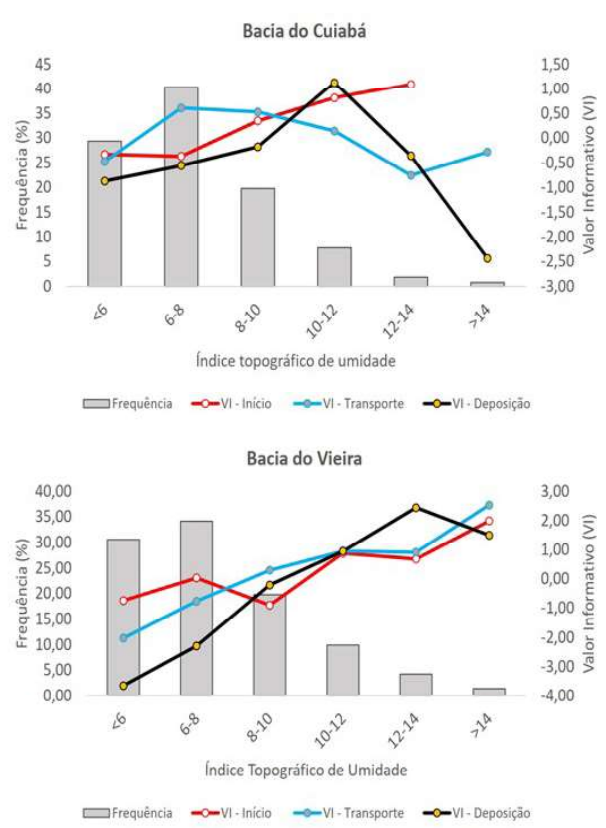

As bacias analisadas apresentaram as feições nos intervalos dos ângulos de encosta mais baixos: Cuiabá $\left(5^{\circ}-10^{\circ}\right)$, Príncipe $\left(2^{\circ}\right)$, Vieira $\left(2^{\circ}-5^{\circ}\right)$ e $D^{\prime}$ Antas $\left(2^{\circ}-\right.$ $5^{\circ}$ ). Este resultado é concordante com estudos anteriores realizados em outros ambientes hidrogeomorfológicos. Por exemplo, o CPRM (2018) reportou que o limite inferior do material de deposição ocorre, geralmente, em terrenos com inclinações superiores a $2^{\circ}$ quando o gradiente e o confinamento são quase nulos.

Os valores de ITU para as áreas de estudo, em relação à Frequência $(\mathrm{F})$, apresentaram predomínio da maior distribuição na segunda classe (6-8) para as bacias de Cuiabá (40\%), Príncipe $(37,7 \%)$, Vieira (34\%) e D'Antas (33,2\%). Nas áreas de estudo, em relação ao mesmo índice, predominam a menor distribuição na sexta classe $(>14)$ para as bacias de Cuiabá $(0,7 \%)$, Príncipe $(0,8 \%)$, Vieira $(1,4 \%)$ e D’Antas $(1,4 \%)$ (Figura 7 ).
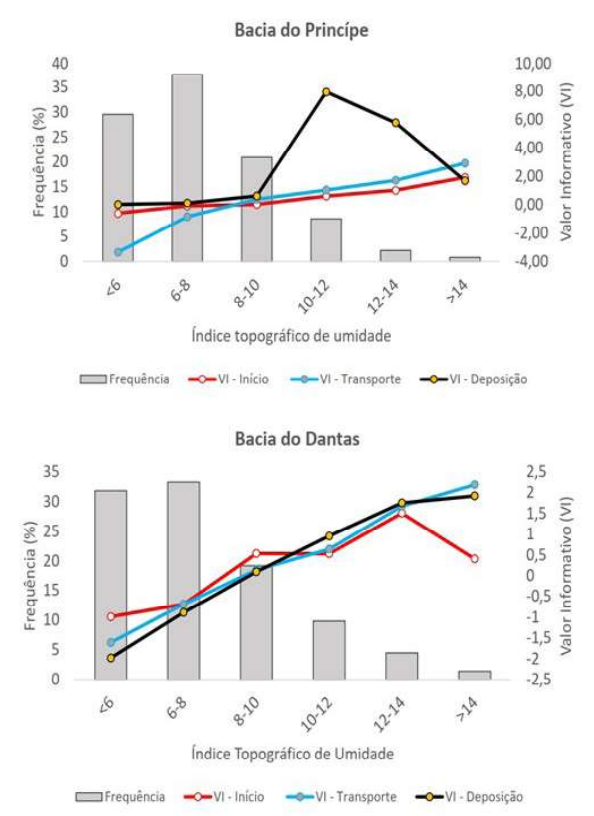

Figura 7 - Aplicação do método do Valor Informativo: Frequência de fluxos de detritos em função dos intervalos de Índice topográfico de Umidade.

Observando os valores de VI, as zonas de erosão (início e transporte) dos fluxos de detritos nas bacias de estudo foram caracterizadas por escorregamentos em encostas íngremes e valores altos de ITU. A concentração da maior distribuição ocorreu na sexta classe $(>14)$, exceto na zona de transporte da bacia Cuiabá (classes 6-8). As zonas de deposição do fluxo de detritos nas bacias de estudo foram caracterizadas por valores altos de ITU: Cuiabá (10-12), Príncipe (10-12), Vieira (12-14) e D'Antas (6-8). Contudo, quando aplicado em áreas planas, onde a inclinação é igual a zero, esse índice culminou em alguns erros matemáticos visto a impossibilidade da divisão. Assim, com base no ITU, entende-se a importância do desenvolvimento do perfil de solo e das águas subterrâneas disponíveis para iniciar um escorregamento de terra seguido de fluxo de detritos. 
Ademais, diversos pesquisadores aplicaram o ITU para predizer locais suscetíveis a fluxos de detritos (GABET \& MUDD, 2006; CHEN \& YU, 2011). Porém, os resultados do cálculo da medida de saturação dos solos estimados pelo ITU não foram padrão para as áreas selecionadas nos estudos desses pesquisadores; ora apresentavam valores elevados de ITU para as áreas mapeadas e ora áreas com valores relativamente baixos de ITU estavam relacionadas à maior suscetibilidade de fluxo de detritos. Logo, o limite crítico do ITU para análise da distribuição espacial de fluxo de detritos nas bacias analisadas pode estar associado à influência da espessura e permeabilidade do solo, das descontinuidades nas encostas e influências de mais de um fenômeno na mesma bacia.

Os valores de IPUC para as áreas de estudo, em relação à Frequência $(\mathrm{F})$, apresentaram predomínio da maior distribuição na terceira classe (3-5) para as bacias de Cuiabá (33,8\%), Príncipe (34,4\%), Vieira (34,5\%) e D'Antas $(78,8 \%)$. Nas áreas de estudo, em relação ao mesmo índice, predominam a menor distribuição na quinta classe (7-12) para as bacias de Cuiabá (3,6\%), Príncipe $(4,4 \%)$, Vieira (4,3\%) e D'Antas (7,6\%) (Figura 8).

No que se refere ao VI (Figura 8), as zonas de erosão (início e transporte) dos fluxos de detritos nas bacias de estudo foram caracterizadas por valores altos de IPUC. As zonas de deposição do fluxo de detritos nas bacias de estudo foram caracterizadas por valores altos de IPUC (7-12), exceto para bacia Príncipe e Vieira $(<1)$. Contudo, quando aplicado em áreas planas, onde a inclinação é igual a zero, esse índice culmina em alguns erros matemáticos visto a impossibilidade da divisão.
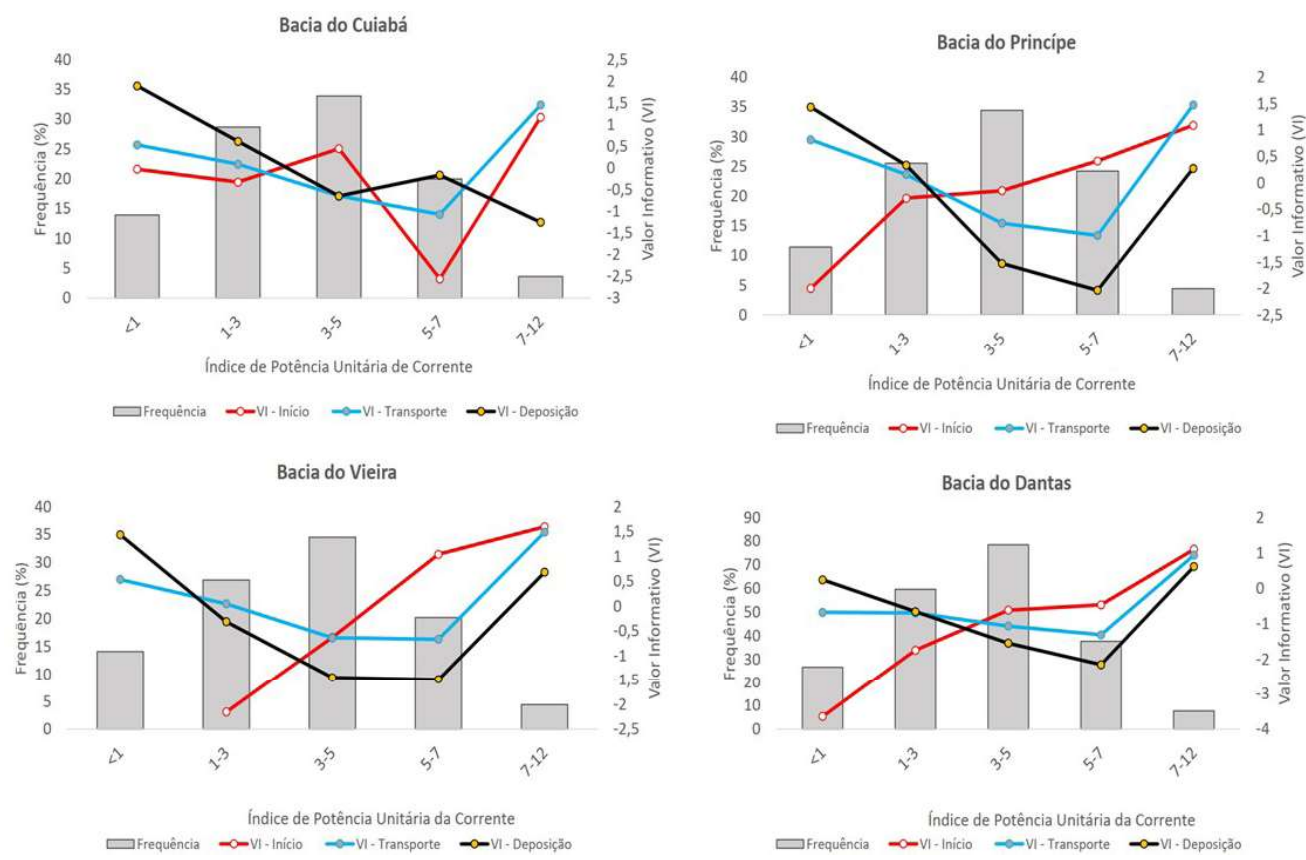

Figura 8 - Aplicação do método do Valor Informativo: Frequência de fluxos de detritos em função dos intervalos de Índice de Potência Unitária de Corrente.

Os valores de LS para as áreas de estudo, em relação à Frequência $(F)$, apresentaram predomínio da maior distribuição na terceira classe (4-6) para as bacias de Príncipe (31\%), Vieira (29\%) e D'Antas (30\%), mas não para a bacia do Cuiabá (2-4). Nas áreas de estudo, em relação ao mesmo índice, predominam a menor distribuição na sexta classe (10-12) para as bacias de Cuiabá $(0,2 \%)$, Príncipe $(0,17 \%)$, Vieira $(0,17 \%)$ e D'Antas (0,06\%) (Figura 8).

Em relação ao VI (Figura 8), as zonas de erosão (início e transporte) dos fluxos de detritos nas bacias de estudo foram caracterizadas por valores altos de LS: Cuiabá e Dantas (8-10) e Príncipe e Vieira (10-12). As zonas de deposição do fluxo de detritos nas bacias de estudo foram caracterizadas por valores baixos de LS (0-2).

De acordo com o método do VI, pôde-se observar uma forte relação de elevada Razão de Frequência relacionada às áreas nas quais os valores do IPUC e LS dos fluxos analisados foram altos para a zona de início 
e transporte (Figuras 8 e 9); esse resultado concorda com os de Tunusluoglu et al. (2007), Chen e Yu (2011) e Gomes (2016), que também associaram a elevação dos valores de IPUC e LS ao aumento da probabilidade de fluxos de detritos.

As bacias Príncipe e Vieira apresentaram baixos valores informativos de potência unitária da corrente e LS para a zona deposição, predominando as feições nos intervalos dos ângulos de encosta mais baixos (média $2^{\circ}$ ). Contudo, as bacias do Cuiabá e D'Antas apresentaram altos valores para IPUC e valores muito baixos para LS, provavelmente por causa da alta frequência de ângulos de encosta superiores a $10^{\circ}$. Baseado na aplicação dos índices IPUC e LS, aparentemente, o uso e a cobertura do solo podem ter um grande impacto na acumulação de materiais no cone de dejeção.
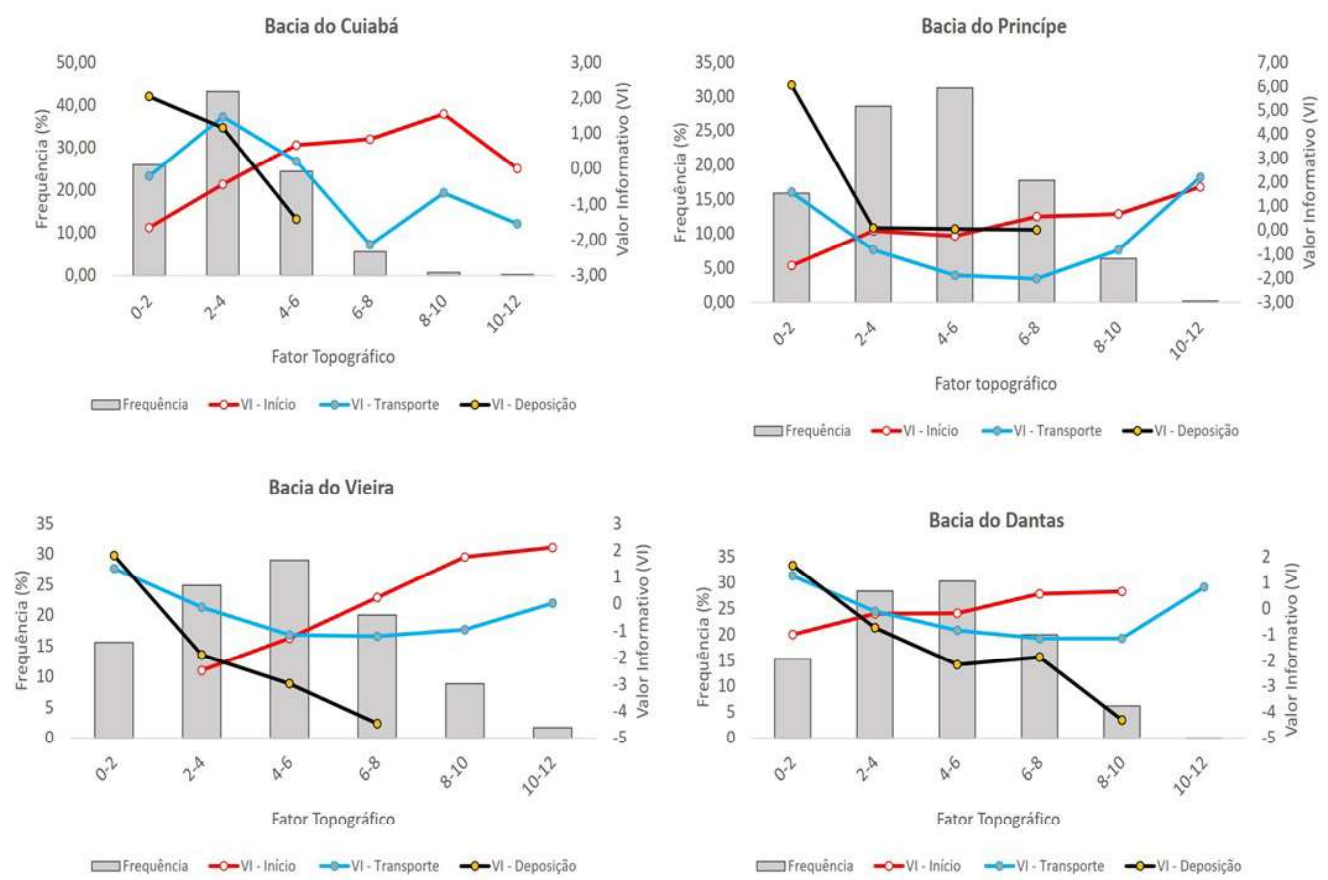

Figura 9 - Aplicação do método do Valor Informativo: Frequência de fluxos de detritos em função dos intervalos de Fator Topográfico.

\section{Conclusões}

Índices morfométricos têm sido aplicados para identificar bacias hidrográficas suscetíveis a fluxo de detritos em diferentes ambientes geomorfológicos no mundo. No presente trabalho, índices morfométricos foram aplicados utilizando estatística bivariada para caracterizar a distribuição espacial de fluxos de detritos (evento de 2011) que afetaram quatro bacias (Cuiabá, Príncipe, Vieira e D'Antas) situadas no reverso da Serra do Mar fluminense nos últimos anos no Estado do Rio de Janeiro.

As investigações de campo possibilitaram a identificação das feições das zonas de acumulação e áreas fontes dos fluxos de detritos. Portanto, a construção de um inventário de movimentos de massa padronizado, no formato de polígono, é imprescindível para a aplicação do modelo estatístico. O mapeamento foi realizado com base em pesquisa bibliográfica, interpretação de ima- gens de satélite e levantamento de campo. O inventário deve passar sempre por uma constante atualização para refinamentos futuros dos produtos dele derivados.

O uso do SIG permitiu que o cálculo dos índices fosse realizado remotamente, sem extensas medições de campo, de forma rápida e barata. Considerando os impactos significativos da resolução do MDT sobre o cálculo dos atributos do terreno, esses índices foram extraídos do MDT (resolução espacial 12,5-m) oriundo da base topográfica IBGE escala 1:25.000. No entanto, para o estudo de fluxo de detritos é necessário assegurar o uso de bases de maior detalhe.

A partir do método do VI foi possível analisar o comportamento dos fatores topográficos dos fluxos de detritos das bacias analisadas. O método do VI sustenta-se na normalização logarítmica da razão entre a probabilidade condicionada de se encontrar algum movimento numa determinada classe de cada fator de 
predisposição (ou variável preditiva) e a probabilidade a priori de que algum evento aconteça na área de estudo (variável dependente). Contudo, ainda são incipientes estudos que abordem o uso deste método para modelar a propagação de fluxos de detritos.

Assim, os resultados alcançados mostram as características dos índices morfométricos Ângulo da Encosta, ITU, IPUC e LS nas áreas de ocorrências de fluxos de detritos, evento de 2011. Os resultados indicam que os fluxos foram deflagrados em amplitude $>1.200 \mathrm{~m}$, ângulos de encosta $>45^{\circ}$, por escorregamentos nos taludes laterais ou na cabeceira de drenagem e desenvolvidos no canal principal com valores altos de ITU, IPUC e LS. Os fluxos de detritos foram depositados em ângulos de encosta $<2^{\circ}$ em bacias com altos valores de ITU e IPUC (exceto Príncipe e Vieira) e baixos valores de LS (LS). Por outro lado, a ocorrência dos fluxos de detritos, ditada pela combinação de diversos condicionantes geológicos e geomorfológicos, ressalta a importância de se considerar em estudos futuros outros aspectos do meio físico (espessura de solo, pontos de estrangulamentos e lineamentos estruturais) e ambiental. Por fim, cabe destacar a necessidade de refinar os dados das variáveis morfométricas e, a partir daí, aperfeiçoar as ferramentas de análise desses processos.

\section{Agradecimentos}

Os autores agradecem à Universidade Federal do Rio de Janeiro e ao Laboratório de Monitoramento e Modelagem Pedogeomorfológica (LAMPEGE) do Departamento de Geografia da UFRJ pelo apoio; e aos revisores da Revista Brasileira de Geomorfologia pelas valiosas contribuições para melhoria do artigo.

\section{Referências Bibliográficas}

ANGILLIERI, E. Debris flow susceptibility mapping in a portion of the Andes and Preandes of San Juan, Argentina using frequency ratio and logistic regression models. Earth Science Research Journal. v. 17, n. 2, p. 159-167, 2013.

ARAÚJO, J. P. C. Análise Morfométrica de Corridas de Detritos na Região Serrana do Estado do Rio de Janeiro: O Estudo de Caso da Bacia Hidrográfica do Córrego D’antas. Dissertação (Mestrado em Geografia) Universidade Federal do Rio de Janeiro, Rio de Janeiro. 2012. 89p.

ARRUDA JR., E. R.; LOPES, E. S. S. Análise morfométrica em sub-bacias hidrográficas para monitoramento do risco potencial a corridas de massa (debris flows) na Região Serrana do Rio de Janeiro. In: $14^{\circ}$ Congresso Brasileiro de Geologia de Engenharia e Ambiental, 2014, Rio de Janeiro. Anais, Rio de Janeiro: ABGE. 2014. p10.

AUGUSTO FILHO, O. O estudo das corridas de massa em regiões serranas tropicais: um exemplo de aplicação no município de Ubatuba, SP. In: $7^{\circ}$ Congresso Brasileiro de Geologia de Engenharia, 1993, Poço de Caldas. Anais, Poços de Caldas: ABGE. 1993. p. 63-72.

BERTRAND, M.; LIÉBAULT, F.; PIÉGAY, H. Susceptibility of small upland catchments to debris flow. In: 12th Congress INTERPRAEVENT, 2012 - Grenoble, France. Conference Proceedings. 2012. p12.

BERTRAND, M. Debris flow susceptibility assessment at the regional scale of the Southern French Alps. Tese (Doutorado Geografia). Ecole Normale Supérieure de Lyon, Lyon. 2014. $163 \mathrm{p}$.

BEVEN, K. J.; KIRKBY, M. J. A. Physically Based Variable Contributing Area Model of Basin Hydrology. In: Hydrological Sciences Bulletin, v. 24, p. 43-69, 1979. https:// doi.org/10.1080/02626667909491834

BOEHNER, J.; SELIGE, T. (2006) Spatial prediction of soil attributes using terrain analysis and climate regionalisation. In: Boehner, J., McCloy, K.R., Strobl, J. [ed.]: SAGA - Analysis and Modelling Applications, Goettinger Geographische Abhandlungen, Goettingen: p. 13-28.

BONHAM-CARTER, G. F. Geographic Information Systems for Geocientists: Modelling with GIS Vol 13. Oxford, Pergamon, 1994. 398p.

BOVIS, M. J.; JAKOB, M. The role of debris supply conditions in predicting debris flow activity. Earth Surface Processes and Landforms, v. 24, n. 11, p. 1039-1054. 1999. https:// doi.org/10.1002/(SICI)1096-9837(199910)24:11<1039::AIDESP29>3.0.CO;2-U

CHEN, C. Y.; LEE, W. J. Topographic features and the initiation of debris flows. In: 10th Congress INTERPRAEVENT 2010 in the Pacific Rim, 2010, Taipei, Taiwan. Symposium Proceedings. 2010. p. 10.

CHEN, C. Y.; YU, C. F. Morphometric analysis of debris flows and their source areas using GIS. Geomorphology, v. 129, p. 387-397, 2011. https://doi.org/10.1016/j.geomorph.2011.03.002

CHEN, C. Y.; CHEN, H. W.; CHEN, Z. J. Determination of Topographic Factors to Initiate Debris Flow Using Statistical 
Analysis. International Journal of Machine Learning and Computing, v. 4, n. 6, p. 547-552, 2014. https://doi.org/10.7763/ IJMLC.2014.V6.471

CHEN, C.Y.; WANG, Q. Debris flow-induced topographic changes: effects of recurrent debris flow initiation. Environmental Monitoring and Assessment, v. 189, 449, 2017. DOI 10.1007/ s10661-017-6169-y

CONFORTI, M; AUCELli, P. P. C.; ROBUSTELli, G. Geomorphology and GIS analysis for mapping gully erosion susceptibility in the Turbolo stream catchment (Northern Calabria, Italy). Natural Hazards, v. 56, p. 881-898, 2011. https://doi.org/10.1007/s11069-010-9598-2

CONQ, M.; SILVEIRA, C. S.; DOURADO, F. Processos geomorfológicos e danos derivados da corrida de detritos de janeiro 2011 na bacia do Córrego do Príncipe, Teresópolis Região Serrana do Rio de Janeiro. Ciência e Natura, v. 37 n. 1, p. 11, 2015. https://doi.org/10.5902/2179460X14872

CORSI, A. C.; GRAMANI, M. F.; OGURA, A. T. Método para delimitação de bacias de drenagem suscetíveis a corrida de massa e enxurrada em regiões serranas. In: $9^{\circ}$ Simpósio Brasileiro de Cartografia Geotécnica e Geoambiental, 2015, Cuiabá. Anais... São Paulo: Abage, 5p.

CPRM, SERVIÇO GEOLÓGICO DO BRASIL (2018). Manual de Mapeamento de Perigo e Risco a Movimentos Gravitacionais de Massa. Projeto de Fortalecimento da Estratégia Nacional de Gestão Integrada de Desastres Naturais (PROJETO GIDES). Acordo de Cooperação Internacional Brasil- Japão [online] Disponível em: < https://www.jica.go.jp/brazil/portuguese/office/ publications/c8h0vm000001w9k8-att/volume1.pdf $\geq$. Acesso em: 20 março 2019.

DE SCALLY, F.; SLAYMAKER, O.; OWENS, I. Morphometric controls and basin response in the Cascade Mountains. Geografiska Annaler, v. 83 n. 3, p 117-130, 2001.

DESMET, P. J.; GOVERS, G. A. GIS procedure for automatically calculating the USLE LS factor on topographically complex landscape units. Journal of Soil and Water Conservation, v. 51, p. 427-433, 1996. https://doi.org/10.1111/j.04353676.2001.00148.x

DIAS, V. C.; VIEIRA, B. C.; GRAMANI, M. F. Parâmetros morfológicos e morfométricos como indicadores da magnitude das corridas de detritos na Serra do Mar Paulista. Revista Franco-Brasileira de Geografia, fls 18, 2015. https://doi. org/10.4000/confins. 11444

DRM-DEPARTAMENTO DE RECURSOS MINERAIS (2011). Megadesastre'11 da Região Serrana do Rio de Janeiro. [online]
Disponível em: <http://www.drm.rj.gov.br $\geq$. Acesso em: 20 janeiro 2018.

ESRI Environmental Systems Research Institute. Online Documentation. Retrieved November 10, 2010, Disponível em: $<$ http://webhelp.esri.com/arcgisdesktop/9.2 $\geq$. Acesso em: 20 janeiro 2018.

FERNANDES, N. F.; GUIMARÃES, R. F.; GOMES, R. A. T.; VIEIRA, B. C.; MONTGOMERY, D. R.; GREENBERG, H. Condicionantes Geomorfológicos dos Deslizamentos nas Encostas: Avaliação de Metodologias e Aplicação de Modelo de Previsão de Áreas Susceptíveis. Revista Brasileira de Geomorfologia, v. 2, p. 51-71, 2001. https://doi.org/10.20502/ rbg.v2i1.8

FERREIRA, C. J.; ROSSINI-PENTEADO, D.; BROLLO, M. J.; PICANÇO, J. L.; DA SILVA, M. C.; GUIMARÃES, B. M. (2016) Debris flow hazard and susceptibility zonation in small watersheds in Itaoca municipality, São Paulo state, Brazil. In: Aversa et al. (Eds). Landslides and Engineered Slopes. Experience, Theory and Practice. Associazione Geotecnica Italiana, Rome: p. 893-900.

FOSTER, G. R.; MEYER, L. D.; ONSTAD, C. A. A runoff erosivity factor and variable slope length exponents for soil loss estimates. Transactions of the American Society of Agricultural Engineers, v. 20, p. 683-687, 1977. https://doi. org/10.13031/2013.35628

GABET, E. J; MUDD, S. M. The mobilization of debris flow from shallow landslides. Geomorphology, v. 74, p. 207-218. 2006. https://doi.org/10.1016/j.geomorph.2005.08.013

GOMES, M. C. V. Corridas de detritos e as taxas de denudação a longo-termo da Serra do Mar/SP. Tese (Doutorado em Geografia Física). Faculdade de Filosofia, Letras e Ciências Humanas, Universidade de São Paulo, São Paulo. 2016. 140p.

GRAMANI, M. F. As corridas de detritos (debris flow) no Ribeirão Cágado, Serra do Mar, Município de Cubatão, SP. In: $6^{\circ}$ Conferência Brasileira de Encostas, 2013, Angra dos Reis. Anais. 2013.

HEILBRON, M.; MACHADO, N.; SIMONETTI, A.; DUARTE, B. P. A Paleoproterozoic Orogen Reworked within the neoproterozoic-Eopaleozoic Ribeira belt, Southern Brazil. In: South American Symposium on Isotope Geology, 2003, Salvador. Short Papers, Salvador, 2003. v. 1, p. 186-189.

HEILBRON, M.; SOARES, A. C. P.; CAMPOS NETO, M. C.; SILVA, L. C.; TROUW, R. A. J.; JANASI, V. A. (2004) Província Mantiqueira. In: MANTESSO-NETO, V.; BARTORELLI, A.; DAL RÉ CARNEIRO, C.; BRITO NEVES, B. (org.). Geologia 
do Continente Sul-Americano: evolução da obra de Fernando Flávio Marques de Almeida. Beca, São Paulo: 203-234 p.

HENGL, T. Finding the Right Pixel Size. Computers \& Geosciences, v. 32, p. 1283-1298, 2006. https://doi. org/10.1016/j.cageo.2005.11.008

HUNGR, O. (2005) Classification and Terminology. In JAKOB, M.; HUNGR, O. (ed.) Debris-flow hazards and related phenomena. Springer, Chichester, UK: p.09-23. https://doi. org/10.1007/3-540-27129-5_2

HUNGR, O.; LEROUEIL, S.; PICARELLI, L. The Varnes classification of landslides types, an update. Landslides, v. 11, p. 167-194, 2013. https://doi.org/10.1007/s10346-013-0436-y

IMAIZUMI, F.; SIDLE, R. C.; TSUCHIYA, S.; OHSAKA, O. Hydrogeomorphic processes in a steep debris flow initiation zone. Geophysical Research Letters, v. 33, L10404, 2006. doi:10.1029/2006GL026250

JACKSON, L. E.; KOSTASCHUCK, R. A.; MACDONALD, G. M. (1987) Identification of debris flow hazard on alluvial fans in the Canadian Rocky Mountains. In: Costa, J. E.; Wieczorek, G. F. (eds.) Debris flows/avalanches: process, recognition, and mitigation. Reviews in Engineering Geology VII, Geological Society of America, Bolder. https://doi.org/10.1130/REG7-p115

JAKOB, M. Morphometric and geotechnical controls of debris flows: frequency and magnitude in southern British Columbia. Tese (Doutorado em Geografia). Departamento de Geografia, Universidade de Columbia Britânica, Canadá, 1996. $242 p$.

LEE, S.; TALIB, J. A. Probabilistic landslide susceptibility and factor effect analysis. In: Environmental Geology, v. 47, n. 7, p. 982-990, 2005. https://doi.org/10.1007/s00254-005-1228-z

LIMA, I. F. O Fluxo de massa do Vieira, Teresópolis-RJ, Megadesastre de 2011: Análise das feições sedimentológicas e de sua fenomenologia. Dissertação (Mestrado em Geologia). Programa de Pós-graduação em Análise de Bacias e Faixas Móveis, Faculdade de Geologia, Universidade do Estado do Rio de Janeiro, Rio de Janeiro. 2013. 75p.

MCCOOL, D. K.; BROWN, L. C.; FOSTER, G. R. Revised slope steepness factor for the Universal Soil Loss Equation. Transactions of the American Society of Agricultural Engineers, v. 30, n. 5, p. 1387-1396, 1987. https://doi. org/10.13031/2013.30576

MELO, R.; ZÊRERE, J. L. Avaliação da suscetibilidade à rutura e propagação de fluxos de detritos na bacia hidrográfica do rio Zêzere (Serra da Estrela, Portugal). Revista Brasileira de Geomorfologia, v. 18, n. 1, p. 81-106, 2017. https://doi. org/10.20502/rbg.v18i1.985

MELO, R. C.; DOURADO, F.; VAREJÃO, L. C.; SILVA, A. F. A Corrida de Massa do Vale do Cuiabá, em Itaipava/Petrópolis - Análise dos Condicionantes Geológicos. In: SIMPÓSIO DE GEOLOGIA DO SUDESTE, 12, 2011, Nova Friburgo. Anais... Nova Friburgo: SBG: 2011.p. 11

MIZUHARA, K. Data Analysis for Predicting the Magnitude of Debris Flow. Journal of the Japan Society of Erosion Control Engineering, v. 48, n. 5, p. 3-10, 1996.

MOORE, I. D.; BURCH, G. J. Modeling erosion and deposition: Topographic effects. Transactions of the American Society of Agricultural Engineers, v. 29, p. 1624-1640, 1986. https://doi. org/10.13031/2013.30363

MOORE, I. D; GRAYSON, R. B; LADSON, A. R. Digital terrain modelling: A review of hydrological, geomorphological, and biological applications. Hydrological Processes. v. 5, n. 1, p. 3-30, 1991. https://doi.org/10.1002/hyp.3360050103

MOORE, I. D.; WILSON, J. P. Length-slope factors for the revised universal soil loss equation: simplified method of estimation. Journal of Soil and Water Conservation, v. 47, n. 5, p. 423-428, 1992.

MUSGRAVE, G. W. The Quantitative Evaluation of Factors in Water Erosion- A First Approximation. Journal of Soil and Water Conservation, v. 2, p. 321-327, 1947.

NERY, T. D. Dinâmica das corridas de detritos no Litoral Norte de São Paulo. Tese (Doutorado). Faculdade de Filosofia, Letras e Ciências Humanas da Universidade de São Paulo. Departamento de Geografia, São Paulo. 2016. 164p.

NUNES, A. L. L. S.; SAYÃO, A. S. F. J. Debris flows e técnicas de mitigação e convivência. In: VI Conferência Brasileira de Encostas - COBRAE, 2014, Anais... Angra dos Reis. 2014. p. 74-96.

O'CALLAGHAN, J.F. AND MARK, D.M. (1984) The Extraction of Drainage Networks from Digital Elevation Data. Computer Vision, Graphics and Image Processing, 28, 328344. http://dx.doi.org/10.1016/S0734-189X(84)80011-0

PICANÇO, J. L.; TANAKA, H. S.; MESQUITA, M. J.; COSTA, V. V.; LUIZ, E. F. O.; LOPES, A. B. B.; AFONSO, F. K.; PIMENT, V. Debris flow hazard zonation in Serra da Prata Range, Paraná State, Brazil: Watershed morphometric Constrain. Landslide and Engineered Slopes. Experience, Theory and Practice. In: Proceedings of the 12th International Symposium on Landslides, 2016, Napoli. Anais...2016. 
PIEDADE, A.; ZÊZERE, J. L.; GARCIA, R. A. C., OLIVEIRA, S. C. Modelos de susceptibilidade a deslizamentos superficiais translacionais na região a norte de Lisboa. Finisterra, v. 46, n. 91, pp. 9-26, 2011.

PILESJÖ, P.; HASAN, A. A. Triangular form-based multiple flow algorithm to estimate overland flow distribution and accumulation on a digital elevation model. Transactions in GIS, v. 18, n. 1, p. 108-124, 2014. https://doi.org/10.1111/tgis.12015 PINTO, R. W. P.; MOTTA, M.; SANTANA, M.; SALLES, R. O.; FRAIFELD, F.; WALDHERR, F.; AMARAL, C. Resultados recentes dos estudos da Corrida de Lama do córrego D'antas, em Nova Friburgo. In: SIMPÓSIO DE GEOLOGIADO SUDESTE, 12, 2011, Nova Friburgo. Anais. Nova Friburgo: SBG, 2011.

QUIN, P.; BEVEN, K.; CHEVALIER, P.; PLANCHON, O. The prediction of hillslope path for distributed hydrological modeling using digital terrain models. Hydrological Processes, v.5, p. 59-79, 1991. https://doi.org/10.1002/hyp.3360050106

RICKENMANN, D.; ZIMMERMANN, M. The 1987 debris flows in Switzerland: documentation and analysis. Geomorphology, v.8, p. 175-189, 1993. https://doi. org/10.1016/0169-555X(93)90036-2

RODRIGUES, J. C.; AMARAL, C. P.; TUPINAMBA, M. Megadesastre '11 da Serra Fluminense: A corrida de massa do Vieira, em Teresópolis - Análise Preliminar Condicionantes Geológicos. In: $13^{\circ}$ Congresso Brasileiro de Geologia de Engenharia, 2011, São Paulo. Anais...São Paulo: ABGE, 2011.

RODRIGUES, J.; TUPINAMBÁ, M.; AMARAL, C. A corrida de massa do rio Vieira em Teresópolis, sudeste do Brasil: caracterização da área fonte dos sedimentos transportados. Anuário do Instituto de Geociências - UFRJ, v. 35, n. 2, p. 152-164, 2012. https://doi.org/10.11137/2012_2_152_164

ROGELIS, M. C.; WERNER, M. Regional debris flow susceptibility analysis in mountainous peri-urban areas through morphometric and land cover indicators. In: Natural Hazards and Earth System Sciences, v. 14, p. 3043-3064, 2014. https:// doi.org/10.5194/nhess-14-3043-2014

SIDLE, R. C.; OCHIAI, H. Landslides: processes, prediction, and land use. Water Resources Monograph 18. Washington: American Geophysical Union, 2006. 312p. https://doi. org/10.1029/WM018

SILVEIRA, C. T.; FIORI, A. P.; FERREIRA, A. M.; GÓIS, J. R.; DE MIO, G.; SILVEIRA, R. M. P.; MASSULINI, N. E. B.; LEONARDI, T. M. H. Emprego de atributos topográficos no mapeamento da susceptibilidade a processos geoambientais na bacia do rio Jacareí, Paraná. Revista Sociedade e Natureza, v. 25, n. 3, pp.623-639, 2013. https://doi.org/10.1590/S198245132013000300014

SMITH, D. D.; WHITT, D. M. Estimating Soil Losses from Field Areas. Agricultural Engineering, v. 29, p. 394-396, 1948.

TUNUSLUOGLU, M. C.; GOKCEOGLU, C.; SONMEZ, H.; NEFESLIOGLU, H. A. An artificial neural network application to produce debris source areas of Barla, Besparmak, and Kapi Mountains (NW Taurids, Turkey). Natural Hazards and Earth System Sciences, v. 7, p. 557-570, 2007. https://doi.org/10.5194/ nhess-7-557-2007

VAN WESTEN, C. J. Application of Geographic Information Systems to Landslides Hazard Zonation. Tese (Doutorado). Technical University Delft, International Institute for Aerospace Survey and Earth Sciences, the Netherlands. 1997. 245p.

VIEIRA, B.; DIAS, V. C.; MARTINS, T. D.; PICANÇO, J. (2019) Análises geomorfológicas e a suscetibilidade a corridas de detritos: ferramentas de apoio aos planos de mitigação. In: YOSHIZAKI, H.T.Y.; RODRIGUEZ, C.A.M.; CICCOTTI, L. (org.) Riscos e desastres: caminhos para o desenvolvimento. RiMa Editora, São Carlos: p. 185-203.

VINK, A. Land Use in Advancing Agriculture, vol. X. New York: Springer, 1975. 394p. https://doi.org/10.1007/978-3-64266049-8

WALDHERR, F. R.; TUPINAMBÁ, M.; MOTTA, M.; AMARAL, C.; FRAIFELD, F.; PAIXÃO, R. Megadesastre '11 Da Serra Fluminense: Zonas De Estrangulamento Durante Corrida De Detritos No Córrego Do Príncipe, Em Teresópolis. In: SIMPÓSIO DE GEOLOGIA DO SUDESTE, 12, 2011, Nova Friburgo. Anais... Nova Friburgo: SBG: 2011.

WALDHERR, F. R.; TUPINAMBÁ, M. A dinâmica dos depósitos pretéritos na deflagração de corridas de detritos em eventos catastróficos: a bacia de drenagem do córrego do Príncipe, Teresópolis - RJ. In: VIII Simposio Latinoamericano de Geografia Física \& IV Simposio Iberoamericano de Geografia Fisica, 2014, Santiago. Anais...Santiago. 2014. P 1185-1192.

WELSH, A. Delineating debris-flow hazards on alluvial fans in the Coromandel and Kaimai regions, New Zealand, using GIS. Tese (Doutorado). University of Canterbury, Christchurch. 2008. 203p.

WELSH, A.; DAVIES, T. Identification of alluvial fans susceptible to debris-flow hazards. Landslides, v. 8, p. 183-194, 2011. https://doi.org/10.1007/s10346-010-0238-4

WILFORD, D. J.; SAKALS, M. E.; INNES, J. L.; SIDLE, R. C.; BERGERUD, W. A. Recognition of debris flow, debris flood and 
flood hazard through watershed morphometrics. Landslides, v.1, p. 61-66. https://doi.org/10.1007/s10346-003-0002-0

WISCHMEIER, W. H.; SMITH, D. D. Predicting rainfall erosion losses from cropland east of the Rocky Mountain. Washington, DC: ARS/USDA, 1965.

XU, W.; YU, W.; JING, S.; ZHANG, G.; HUANG, J. Debris flow susceptibility assessment by GIS and information value model in a large-scale region, Sichuan Province (China). Natural Hazards 65(3) February 2013 https://doi.org/10.1007/s10346003-0002-0

YAN, T. Z. Recent advances of quantitative prognoses of landslide in China. In: Bonnard C (ed.) Landslides. Proceedings of the Fifth International Symposium on Landslides, Lausanne, 2, Balkema, Rotterdam: 1263-1268, 1988.
YIN, K. L.; YAN, T. Z. Statistical prediction models for slope instability of metamorphosed rocks. In Bonnard C (ed.) Landslides. Proceedings of the Fifth International Symposium on Landslides, 2, Balkema, Rotterdam: 1269-1272, 1988.

YI WU, C. Numerical Modelling on the motion and deposition behaviors of debris flow. Dissertação (Mestrado), School of Civil Engineering, National Cheng Kung University, Tailândia, 2003.

ZEVENBERGEN, L. W.; THORNE, C. R. Quantitative analysis of land surface topography. Earth Surface Processes and Landforms, v. 12, p. 59-64, 1987. https://doi.org/10.1002/ esp.3290120107

ZINGG, A. W. Degree and length of land slope as it affects soil loss in runoff. Agricultural Engineering, v. 21, p. 59-64, 1940. 